University of Mannheim / Department of Economics Working Paper Series

On the Distribution of Wealth and Employment

Minchul Yum

Working Paper 18-03

March 2018 


\title{
On the Distribution of Wealth and Employment
}

\author{
Minchul Yum*
}

March 2018

\begin{abstract}
In the United States, the employment rate is nearly flat across wealth quintiles with the exception of the first quintile. Correlations between wealth and employment are close to zero or moderately positive. However, incomplete markets models with a standard utility function counterfactually generate a strongly negative relationship between wealth and employment. Using a fairly standard incomplete markets model calibrated to match the distribution of wealth, I find that government transfers and capital income taxation increase the (non-targeted) correlations between wealth and employment substantially, bringing the model closer to the data. As the model's fit with the distribution of wealth and employment improves, I find that the precautionary motive of labor supply is mitigated, thereby raising aggregate labor supply elasticities substantially.
\end{abstract}

Keywords: Wealth distribution; employment; government transfers; capital income taxation; aggregate labor supply elasticity

JEL codes: E24, E21, J22

\footnotetext{
${ }^{*}$ Department of Economics, University of Mannheim, Germany, e-mail: minchul.yum@uni-mannheim.de. I am grateful to Timo Boppart, Patrick Pintus, and Arnau Valladares-Esteban for their constructive discussions. I also thank Klaus Adam, Florin Bilbiie, Michael Burda, Antoine Camous, Sebastian Findeisen, Jordi Gali, Tom Krebs, Dirk Krueger, Per Krusell, Dmitry Matveev, Kjetil Storesletten, Nicola Pavoni, Shuhei Takahashi, Michele Tertilt, and seminar participants at the GRIPS-Keio Macroeconomics and Policy Workshop, Kyoto University, the European Winter Meeting of the Econometric Society at Barcelona GSE, 8th ifo Conference on Macroeconomics and Survey Data, Sogang University, NorMac 2017, Asian Meeting of the Econometric Society in Hong Kong, Madrid Workshop in Quantitative Macroeconomics, Humboldt University of Berlin, T2M conference in Lisbon, the PSE/Banque de France/Fondation France-Japon-EHESS workshop and the University of Mannheim for helpful comments. Finally, I thank Youngsoo Jang for the help with the SIPP data. An earlier version of the paper was circulated under the title of "On the Distribution of Wealth and Labor Force Participation."
} 


\section{Introduction}

Several recent studies have shown that labor supply at the extensive margin is nearly flat across wealth quintiles in the United States. ${ }^{1}$ In fact, I find that employment rates over wealth quintiles are nearly flat with the exception of the first quintile in the Survey of Consumer Finances (SCF) data set that has been recognized as one of the best data sets capturing a highly concentrated distribution of wealth. ${ }^{2}$ Moreover, correlations between wealth and employment are close to zero or moderately positive. However, these empirical facts are in sharp contrast to standard incomplete markets models with a standard household preference since these models predict that the employment rate falls sharply with wealth. ${ }^{3}$ Does this discrepancy imply that the degree of wealth effects on extensive margin labor supply, implied by the utility function commonly assumed in the macroeconomic models, is not compatible with the data? Or, are there any missing factors in the standard model that are crucial for this discrepancy?

The main goal of this paper is to explore the role of institutional factors such as government transfers and capital income taxation in resolving this discrepancy while maintaining the standard utility function. To this end, I develop a fairly standard incomplete markets model in which consumption-savings and labor supply at the extensive margin are endogenous. The model economy is calibrated to match the highly concentrated distribution of wealth in the SCF data in the spirit of Castaneda, Diaz-Gimemez and Rios-Rull (2003) and Kindermann and Krueger (2016). Using the model economy, I show that government transfers and capital income taxation are quantitatively important in rendering the model much more consistent with the data in terms of non-targeted statistics about the cross-sectional relationship between wealth and employment. Specifically, the rank correlation between wealth and employment implied by the model increases from -0.50 in the standard version of the incomplete markets model to 0.14 in the baseline specification that

\footnotetext{
${ }^{1}$ See e.g., Chang and Kim (2007) and Ferriere and Navarro (2016) for the evidence in the Panel Study of Income Dynamics; and Mustre-del-Rio (2015) for the evidence in the National Longitudinal Survey of Youth. Note that labor supply at the extensive margin may represent employment or labor force participation decisions. This paper focuses on the full-time employment margin, which is conceptually closer to labor supply in a class of macroeconomic models considered in this paper. The empirical pattern documented herein is similar for labor force participation decisions as well except for the first wealth quintile.

${ }^{2}$ See e.g., Diaz-Gimenez, Glover, and Rios-Rull (2011); and Kuhn and Rios-Rull (2015) for recent reviews that describe various aspects of inequality in the U.S. using the SCF.

${ }^{3}$ Chang and Kim (2007), Mustre-del-Rio (2015) and Ferriere and Navarro (2016) show that the employment rate strongly declines with wealth quintiles in their model with log utility for consumption and separable disutility of work, the so-called KPR preference (King, Plosser and Rebelo, 1988).
} 
incorporates both transfers and capital income taxation (much closer to 0.07 in the data). In other words, the model is able to reconcile the weakly positive correlations between wealth and employment with the standard utility function featuring reasonable income effects, in the presence of institutional features such as government transfers and capital income taxation.

The economic mechanisms behind the importance of transfers and capital income taxation in resolving the discrepancy are straightforward. A key reason why the standard version of the incomplete markets model predicts a strongly negative rank correlation between wealth and employment is that most of the wealth poor households counterfactually choose to work despite their low productivity. Note that households can self-insure against idiosyncratic productivity risk not only through savings (Imrohoroğlu, 1989; Huggett 1993; Aiyagari, 1994) but also through labor supply (PijoanMas, 2006; Heathcote, Storesletten and Violante, 2008, 2014). Transfers serve as an additional insurance instrument, particularly for those who lack wealth accumulation and thus rely heavily on labor supply for self-insurance. Therefore, the presence of government transfers significantly mitigates the strong precautionary motive of labor supply. As a result, the employment rate of the first wealth quintile becomes $60.2 \%$, closer to $60.8 \%$ in the data. On the other hand, the strongly negative correlation between wealth and employment is also because the employment rate of the wealth rich is too low in the standard version of the incomplete markets model $(42.0 \%)$ compared to the data $(72.3 \%)$. As wealth (and thus capital income) is heavily concentrated among the wealth rich, the presence of capital income taxation disproportionately reduces the asset holdings of the wealth rich, thereby promoting labor supply of these richer households through income effects (resulting in $71.3 \%$ in the baseline specification). Therefore, both transfers and capital taxation play a quantitatively significant role in mitigating the negative slope of employment rates according to wealth.

In light of the quantitative success in better accounting for the distribution of wealth and labor supply, I use the model to explore its implications for the aggregate labor supply elasticity. ${ }^{4}$ Note that, in an incomplete markets model with endogenous labor supply at the extensive margin (e.g., Chang and Kim, 2006, 2007; and Alonso-Ortiz and Rogerson, 2010), it is the distribution of households, not a single utility function parameter, which shapes the aggregate employment

\footnotetext{
${ }^{4}$ The aggregate labor supply elasticity is central to various questions in macroeconomics and related areas, ranging from the efficiency costs of taxation to business cycle fluctuations. See e.g., King and Rebelo (1999), Keane (2011) and Keane and Rogerson (2012) for literature reviews.
} 
response to wage changes. An important contribution has been made by Chang and Kim (2006) who investigate the endogenous distribution of wealth as a determinant of the aggregate labor supply elasticity. A contribution of this paper relative to this literature is to investigate the implications of the joint distribution of wealth and labor supply for the aggregate labor supply elasticity.

For this purpose, the model economy with different specifications is used to explore the implications for the aggregate labor supply elasticity. I consider two exercises. First, I study the effects of permanent labor income tax changes on labor supply, as in Krusell, Mukoyama, Rogerson and Şahin $(2008,2010)$. The quantitative analysis reveals that the aggregate labor supply elasticity, induced by permanently higher labor taxes, is considerably larger when the model better replicates the distribution of wealth and labor supply (0.42 in the baseline specification vs 0.24 in the standard version of the model). The much higher aggregate labor supply elasticity in the baseline model is largely driven by labor supply decisions of households with low productivity, whereas in the standard version of the model, these households are much less sensitive to after-tax wage changes due to the very strong precautionary motive of labor supply. The second exercise considers the aggregate labor supply elasticity, based on the equilibrium distribution of reservation as in Chang and Kim (2006). ${ }^{5}$ I find that this aggregate labor supply elasticity in the baseline model is also substantially higher in the baseline model (1.74) than in the standard version of the model (1.09). These exercises highlight the importance of overturning the counterfactually negative relationship between wealth and employment, since the model would substantially understate the magnitude of aggregate labor supply elasticities.

The cross-sectional relationship between wealth and labor supply has received little attention in the literature. The flat (or weakly inverse U-shaped) employment rates across wealth quintiles in the U.S. I find using data from the SCF are broadly consistent with the existing evidence in Chang and Kim (2007), Mustre-del-Rio (2015) and Ferriere and Navarro (2016) using different data sets such as the NLSY and the PSID. In addition to the flat profile of employment rates by wealth quintiles, my paper also shows that correlations are close to zero or moderately positive within various groups divided by gender, education, age and over time. This clearly demonstrates the discrepancy between the data and standard incomplete markets models, the latter of which are

\footnotetext{
${ }^{5}$ As found by Chang and Kim (2006), the elasticity obtained in this way roughly corresponds to Frisch elasticity for the hypothetical representative agent. As noted by Erosa, Fuster, and Kambourov (2016), Frisch elasticity is not a well-defined concept in incomplete markets with household heterogeneity.
} 
shown to generate strongly negative correlations.

Moreover, there has been almost no attention paid to the theoretical exploration of channels affecting the cross-sectional relationship between wealth and employment. Mustre-del-Rio (2015) is one exception and examines this issue. Using a quantitative model with infinitely-lived two-person households, Mustre-del-Rio (2015) concludes that ex-ante heterogeneity in disutility of work across gender and skills is key in reversing the counterfactual prediction of the model. In this paper, I take an alternative approach in assuming that all households have the same preference, and investigate the role of the observed government transfers and capital tax as key factors shaping the cross-sectional relationship between wealth and labor supply. ${ }^{6}$

This paper builds on the literature that emphasizes the role of government transfers as an insurance mechanism. Hubbard, Skinner, and Zeldes (1995) show that social insurance in the form of government transfers discourages precautionary saving, especially for low-income households. In this paper, I highlight that the role of government transfers as social insurance extends to labor supply decisions, reducing the precautionary motive of labor supply. Broadly speaking, my paper is also related to the literature which emphasizes the role of transfers in affecting labor supply and in understanding macroeconomic aggregates, such as Floden and Linde (2001), Rogerson (2007), Ljungqvist and Sargent (2008), Alonso-Ortiz and Rogerson (2010), and Oh and Reis (2012) among others. It is worth noting that, although there are exisiting papers that consider transfers in a model with endogenous employment such as Alonso-Ortiz and Rogerson (2010) and Krusell et al. (2010), they do not explicitly investigate how the existence of transfers shape the cross-sectional relationship between wealth and labor supply, which is the focus of this paper.

Finally, note that there is a literature that highlights the correlation between wages and intensive-margin hours as a way of measuring the degree of risk-sharing in the absence of complete asset markets (Pijoan-Mas, 2006; and Heathcote, Storesletten and Violante, 2008, 2014). My finding that transfers substantially increases correlations between wealth and employment is accompanied by a more positive correlation between productivity and employment. This demonstrates

\footnotetext{
${ }^{6}$ Mustre-del-Rio (2015) considers a form of transfers (minimum consumption) although it is not the main focus of his paper. In addition to the apparent modeling difference, a key difference lies on the nature of the quantitative exercise. Specifically, transfers in my model are calibrated to be consistent with the data, but are not directly targeted to match the wealth profile of employment. Therefore, the effect of introducing government transfers on the wealthemployment relationship is one of the non-targeted moments, and the evaluation of this effect is one of the main exercises in my paper. In contrast, the minimum consumption level in Mustre-del-Rio (2015) is directly targeted to match the employment rate of men in the first wealth quintile when the model is calibrated.
} 
that the key insight in this literature extends to my incomplete markets setting in which labor supply at the extensive margin becomes more positively correlated with productivity (or wage if households choose to work) in the presence of transfers which enhance self-insurance against idiosyncratic productivity shocks.

The paper is organized as follows. The next section documents the cross-sectional relationship between wealth and employment using data from the SCF. Section 3 presents the environment of the model economy. Section 4 explains how the model is calibrated across different specifications. Section 5 presents the main quantitative analysis regarding the distribution of wealth and labor supply in the model compared to the data. I also briefly discuss the effects of alternative utility specifications. Section 6 explores the implications of better matching the cross-sectional relationship between wealth and employment for the aggregate labor supply elasticity. Section 7 concludes.

\section{Wealth and employment in the United States}

The key statistics of interest in this paper regard the cross-sectional relationship between wealth and employment. This section uses the 1992-2007 waves of the Survey of Consumer Finances (SCF) to document their relationship in the U.S. A distinguishing feature of the SCF is that it collects detailed information about various household assets and liabilities, particularly of those who are at the upper tail. Hence, the SCF is often recognized as one of the best household surveys to capture a highly concentrated distribution of wealth in the U.S. The facts documented in this section are based on pooled samples from the six waves of the SCF (1992-2007) whose age is between 18 and $70 .{ }^{7}$ Wealth is defined as the net worth, which is the sum of financial and non-financial asset holdings minus total liabilities. Employment is a binary variable and takes the value of one if the household head's the annual total hours worked is greater than 1,000 and the value of zero otherwise. In all statistics, survey weights are used and dollar amounts are adjusted to 2013 dollars. More details about data are available in Appendix.

Figure 1 plots employment rates by wealth quintiles in U.S. data. At first glance, the profile of employment rates seems quite flat across wealth quintiles around the overall employment rate

\footnotetext{
${ }^{7}$ I exclude households whose age is greater than 70 since it is less likely for them to use the labor supply margin actively for various reasons (e.g., due to health). However, the key facts documented in this section are quite robust to the inclusion of these samples.
} 
Figure 1: Participation rates by wealth quintiles in the US

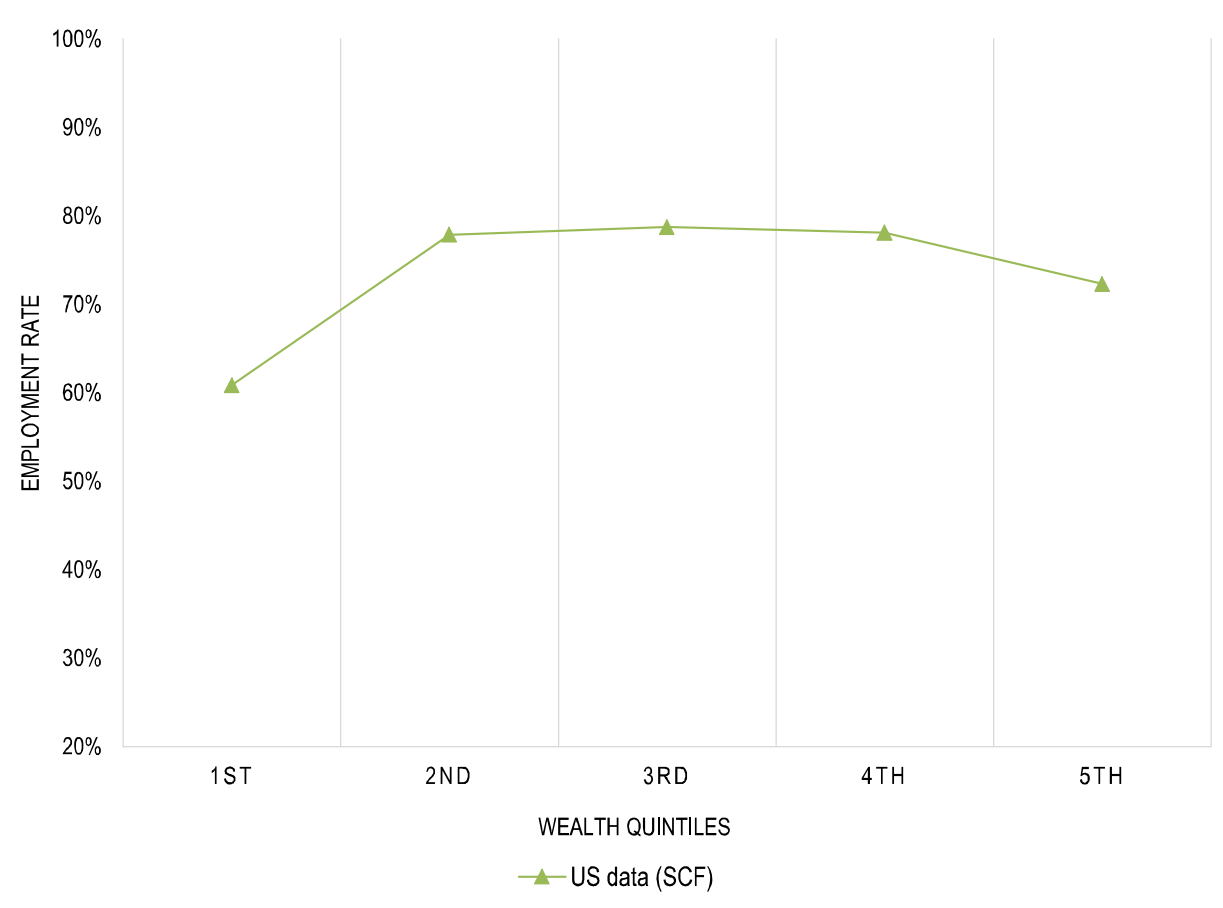

Note: This figure is based on the 1992-2007 waves of the Survey of Consumer Finances. Survey weights are used and wealth is adjusted for inflation.

of $73.6 \%$. A closer look reveals that it is weakly inverse U-shaped. Specifically, the employment rate of households in the first wealth quintile is somewhat lower at $60.8 \%$. On the other hand, the employment rates in the second and the third quintiles are relatively higher at $77.9 \%$ and $78.7 \%$, respectively. Then, the employment rate declines weakly as we move toward richer households (72.3\% at the top wealth quintile). However, the overall shape of the employment rate across wealth quintiles is nearly flat, especially among households except the first wealth quintile. This relatively flat profile I find in the SCF data set is broadly consistent with the existing evidence based on different data sets such as the NLSY and the PSID (Chang and Kim, 2007; Mustre-del-Rio 2015; and Ferriere and Navarro, 2016).

To quantitatively establish the relationship between wealth and employment, it is helpful to present correlations between the two variables. Table 1 reports cross-sectional correlations between wealth and employment using the same data set. In addition to the conventionally used Pearson 
Table 1: Correlations between wealth and employment

\begin{tabular}{lcc}
\hline \hline & Spearman & Pearson \\
\hline Overall & $\mathbf{0 . 0 7}$ & $\mathbf{- 0 . 0 2}$ \\
& & \\
By gender & & \\
- Male & 0.00 & -0.04 \\
- Female & 0.12 & -0.01 \\
& & \\
By education & & \\
- No college & 0.07 & -0.03 \\
- Some college & 0.02 & -0.05 \\
- College & -0.07 & -0.08 \\
& & \\
By age & & \\
- Young (29 or below) & 0.22 & 0.03 \\
- Middle (30-54) & 0.24 & 0.03 \\
- Old (55 or above) & 0.10 & 0.01 \\
& & \\
By year & & \\
- 1992 & & \\
- 1995 & 0.07 & -0.01 \\
- 1998 & 0.07 & -0.02 \\
- 2001 & 0.05 & -0.03 \\
- 2004 & 0.06 & -0.05 \\
- 2007 & 0.05 & -0.04 \\
\hline
\end{tabular}

Note: Spearman's correlation is a nonparametric measure of statistical dependence between the ranking of wealth and that of employment whereas Pearson's correlation captures the statistical dependence between the levels of the two variables. The data source is the 1992-2007 waves of the Survey of Consumer Finances. Survey weights are used and wealth is adjusted for inflation.

correlation coefficient that captures the strength of linearity, I also report Spearman's correlation coefficient that uses the rank of each variable instead of the level. Note that when wealth is highly dispersed, Pearson's correlation is largely affected by the wealth-rich whereas Spearman's correlation is not.

The first row of Table 1 reveals that Spearman's correlation is moderately positive at 0.07 and Pearson's correlation is slightly negative (-0.02). As highlighted in Introduction, the near-zero or even moderately positive correlations in the data are at odds with standard incomplete markets model with a standard household preference since the model would predict that correlations between 
wealth and employment are considerably negative. ${ }^{8}$

Table 1 also reports correlations within more disaggregated groups. First, it is interesting to note that even within narrower groups divided by gender and education (as shown in the second to sixth rows of Table 1), correlations between wealth and employment stay relatively close to zero. The rank correlation (Spearman) between wealth and employment ranges from -0.07 (for college graduates) to 0.12 (female), but they are mostly around zero in many different groups. Pearson's correlations are in general more negative, but they are not far from zero. Note that both Spearman and Pearson correlations are more positive among the low-education group whereas they are more negative among the high-education group. This pattern should not be surprising given Figure 1, which shows the weakly inverse U-shaped employment profile over wealth, the latter of which is positively correlated with the education level. ${ }^{9}$

Interestingly, when correlations are computed within different age groups, the rank correlation becomes more positive, ranging from 0.10 to $0.24 .{ }^{10}$ This, in fact, makes the discrepancy between the model and the data even more puzzling since the standard model implies strongly negative rank correlations. Finally, Table 1 also reports correlations for each year. Spearman's correlation coefficient ranges from 0.05 to 0.07 and Pearson's correlation coefficient ranges from -0.05 to -0.01 over time. Therefore, these estimates clearly demonstrate that the correlations are very robust over time.

\section{Model economy}

In this section, I describe the model economy that will be used (i) to illustrate the counterfactual prediction of a standard incomplete markets model regarding the relationship between wealth and employment; and (ii) to explore the role of transfers and capital income tax in rendering the model more consistent with the data. It is a relatively standard incomplete markets general equilibrium model with heterogeneous households in the tradition of Huggett (1993) and Aiyagari (1994). Several key features include uninsurable idiosyncratic shocks along with incomplete asset markets

\footnotetext{
${ }^{8}$ As I investigate in more detail in Section 5, my calibrated model representing a standard incomplete markets model implies the Spearman and Pearson correlations of -0.50 and -0.20 , respectively.

${ }^{9}$ The mean net worth among the college group (the some-college group) is 5.0 (1.7) times as large as that among the no-college group.

${ }^{10}$ Nevertheless, the Pearson correlations within age groups are still relatively close to zero.
} 
and borrowing constraints, which result in households' precautionary savings for self-insurance. Another key feature in the model economy considered in this paper is the endogenous labor supply at the extensive margin (i.e., employment) (Chang and Kim, 2006). The model environment described below is the baseline specification that incorporates government transfers and capital taxation. In the following quantitative analysis, I will also consider alternative specifications which are simply nested specifications of the baseline model to represent a standard version of the incomplete-markets model.

\section{Households:}

The model economy is populated by a continuum of infinitely-lived households. Since the analysis in this paper is based on a stationary environment, I omit the time index and present the household's dynamic decision problem recursively. In each period, households are distinguished by their net worth $a$ and productivity $x_{i}$. I assume that $x_{i}$ takes a finite number of values $N_{x}$ and follows a Markov chain with transition probabilities $\pi_{i j}$ from the state $i$ to the state $j$. The competitive factor markets imply that households take as given the wage rate per efficiency unit of labor $w$ and the real interest rate $r$. The dynamic decision problem which each household faces in each period is captured by the following discrete choice problem:

$$
V\left(a, x_{i}\right)=\max \left[W\left(a, x_{i}\right), N\left(a, x_{i}\right)\right]
$$

where $W\left(a, x_{i}\right)$ is the value of working and $N\left(a, x_{i}\right)$ is the value of non-working. Each of these value functions are defined as

$$
\begin{aligned}
& W\left(a, x_{i}\right)=\max _{c \geq 0, a^{\prime}>\underline{a},}\left\{U(c, \bar{n})+\beta \sum_{j=1}^{N_{x}} \pi_{i j} V\left(a^{\prime}, x_{j}^{\prime}\right)\right\} \\
& \text { subject to } c+a^{\prime} \leq\left(1-\tau_{l}\right) w x_{i} \bar{n}+\left(1+r\left(1-\tau_{k}\right)\right) a+T(z) \quad \text { if } a>0 \\
& \leq\left(1-\tau_{l}\right) w x_{i} \bar{n}+(1+r) a+T(z) \quad \text { if } a \leq 0
\end{aligned}
$$


and

$$
\begin{aligned}
& \qquad \begin{aligned}
N\left(a, x_{i}\right)=\max _{c \geq 0, a^{\prime}>\underline{a}},\left\{U(c, 0)+\beta \sum_{j=1}^{N_{x}} \pi_{i j} V\left(a^{\prime}, x_{j}^{\prime}\right)\right\} \\
\text { subject to } c+a^{\prime} \leq\left(1+r\left(1-\tau_{k}\right)\right) a+T(z) \text { if } a>0 \\
\leq(1+r) a+T(z) \text { if } a \leq 0,
\end{aligned}
\end{aligned}
$$

thereby making the whole problem as a functional equation for $V\left(a, x_{i}\right)$. In each case, households maximize utility by choosing the optimal consumption $c$ and asset holding for the next period $a^{\prime}$ conditional on the labor supply decision while taking into account the expected future value $\sum_{j=1}^{N_{x}} \pi_{i j} V\left(a^{\prime}, x_{j}^{\prime}\right)$ discounted by a discount factor $\beta .^{11}$

The budget constraint states that the sum of current consumption $c$ and assets for the next period $a^{\prime}$ should be less than or equal to the available resources at the beginning of the current period, as shown in (1)-(4). The available resources (i.e., the right-hand side of the budget constraints) depend on the labor supply choice. When households choose to work, the available resources include net-of-tax earnings $\left(1-\tau_{l}\right) w x_{i} n$, current asset holdings $a$, net-of-tax capital income $\left(1-\tau_{k}\right) r a$, and government transfers $T(z) . T(\cdot)$ is the nonlinear transfer schedule determinig the amount of transfers as a function of $z$, which is the ratio of household income to output per capita. ${ }^{12}$ When they choose not to work, the available resources exclude earnings. As shown in (2) and (4), when $a$ is non-positive, households are not subject to capital income taxation. Households can borrow up to a borrowing limit $\underline{a} \leq 0$.

Finally, I assume that the period utility function follows

$$
U(c, n)=\log (c)-\Gamma n
$$

where $\Gamma>0$ is the disutility of work as a parameter. Note that this utility function belongs to the so-called KPR preference (King et al. 1988). The KPR preference is widely used in the applied macroeconomics literature since it permits the balanced growth path with reasonably strong income effects.

\footnotetext{
${ }^{11} \mathrm{~A}$ variable with a prime denotes its value in the next period.

${ }^{12}$ Household income is the sum of earnings and capital income. Details on government transfers are described in the description of government below.
} 


\section{Government:}

The government taxes labor earnings at the rate of $\tau_{l}$ and capital income at the rate of $\tau_{k}$. The tax revenues are redistributed to households in the form of transfers. The U.S. transfers exhibit progressivity, as discussed in Section 4. In the spirit of means-tested programs such as food stamps, the Supplemental Nutrition Assistance Program (SNAP) and the Temporary Assistance for Needy Families (TANF; formerly the Aid to Families with Dependent Children), the amount of transfers is allowed to depend on household income using the following nonlinear transfer schedule:

$$
T(z)=\lambda_{s}(1+z)^{-\lambda_{p}} .
$$

where $\lambda_{s}$ and $\lambda_{p}$ are fiscal parameters and $z$ denotes the ratio of household income (labor earnings and capital income) to output per capita. ${ }^{13}$ The first fiscal parameter $\lambda_{s} \geq 0$ defines the amount of transfers for households with zero income (i.e., $T(0)=\lambda_{s}$ ), and given $\lambda_{p} \geq 0$, the size of transfers decreases weakly with household income. In this sense, $\lambda_{s}$ adjusts the scale of transfers, and $\lambda_{p}$ captures the degree of progressivity. Note that for $\lambda_{p}=0$ the amount of transfers is independent of household income, while for a larger value of $\lambda_{p}$ the amount of transfers would decrease faster with household income. Although the above parametric form is simple, Section 4 shows that it approximates the heterogeneity in the amount of transfers across income quintiles in the U.S. very well.

The government purchase $G$ is residually determined such that the government budget constraint is balanced. Since the role of government purchase on labor supply is out of scope of this paper, I assume that $G$ is either not valued by households or valued by households in an additively separable manner.

\section{Firm:}

Aggregate output $Y$ is produced by a representative firm. The firm maximizes its profit

$$
\max _{K, L}\{F(K, L)-(r+\delta) K-w L\}
$$

\footnotetext{
${ }^{13}$ Heathcote et al. (2016) estimate the progressivity of the tax and transfer system jointly among the workers. As noted by the authors, their parametric assumption imposes zero net transfers for those who have zero earnings. Therefore, their tax and transfer system is not ideal for the framework considered in this paper wherein the focus is on the extensive margin labor supply because no social insurance is provided to the wealth poor who do not work.
} 
where $F(K, L)$ captures a standard neoclassical production technology in which $K$ denotes aggregate capital, $L$ denotes aggregate efficiency units of labor inputs, and $\delta$ is the capital depreciation rate. The aggregate production function is assumed to be a Cobb-Douglas function with constant returns to scale:

$$
F(K, L)=K^{\alpha} L^{1-\alpha}
$$

The above optimization problem provides the factor demand for capital $K^{d}$ and labor $L^{d}$ satisfying

$$
\begin{aligned}
r & =F_{1}\left(K^{d}, L^{d}\right)-\delta \\
w & =F_{2}\left(K^{d}, L^{d}\right) .
\end{aligned}
$$

\section{Equilibrium:}

A stationary recursive competitive equilibrium is a collection of factor prices $r, w$, equilibrium aggregate quantities $K, L$, the household's decision rules $g\left(a, x_{i}\right), h\left(a, x_{i}\right)$, government policies $\tau_{l}, \tau_{k}, T(\cdot), G$, value functions $V\left(a, x_{i}\right), W\left(a, x_{i}\right), N\left(a, x_{i}\right)$ and a probability measure of households $\mu$ over the state space such that

1. Given factor prices $r, w$ and government policy $\tau_{l}, \tau_{k}, G, T(\cdot)$, the value functions $V\left(a, x_{i}\right)$, $W\left(a, x_{i}\right), N\left(a, x_{i}\right)$ solve the household's decision problems defined above, and the associated household decision rules are $g\left(a, x_{i}\right)$ and $h\left(a, x_{i}\right)$;

2. Given factor prices $r, w$, the firm optimally chooses the factor demands $K^{d}$ and $L^{d}$ following (7) and (8);

3. Markets clear;

$$
\begin{aligned}
\int g\left(a, x_{i}\right) d \mu & =K^{d}=K \\
\int x_{i} h\left(a, x_{i}\right) d \mu & =L^{d}=L
\end{aligned}
$$


4. Government balances its budget:

$$
G+\int T(z) d \mu=\tau_{l} w L+\tau_{k} r \int I(a \geq 0) g\left(a, x_{i}\right) d \mu
$$

where $I(a \geq 0)$ is an indicator function being one if $a \geq 0$ and zero otherwise;

5. The measure of households $\mu$ over the state space is the fixed point given the decision rules and the stochastic processes governing $x_{i}$.

\section{Setting model parameters}

The model is calibrated to U.S. data, based on the Survey of Consumer Finances (SCF) and the Survey of Income and Program Participation (SIPP). As in Alonso-Ortiz and Rogerson (2010), a model period is set to one year. Note that the key flow statistics obtained from the data, such as the hours worked and earnings, are based on the annual frequency. ${ }^{14}$ There are two sets of parameters. The first set of parameters is calibrated externally. These parameter values are fixed across different specifications. The second set of parameters is calibrated to match the target statistics obtained from the micro-level data. These parameter values are re-calibrated across different specifications so that the different specifications are comparable to each other in terms of key macroeconomic variables and the degree of inequality generated by the model. The model-implied statistics should be obtained numerically since the model cannot be solved analytically. The equilibrium decision rules and the value functions of households are computed using a standard nonlinear method. ${ }^{15}$

Before I discuss how the parameters are calibrated, it is necessary to specify the labor productivity processes. Note that the literature has found that a standard incomplete markets model requires extra features to replicate a very high degree of wealth inequality observed in the SCF. ${ }^{16}$

\footnotetext{
${ }^{14}$ Given the assumption on indivisible labor, I have experimented with a version of the model with a higher model frequency (i.e., quarterly). The main results are quite robust, mainly because this paper focuses on long-run (steadystate) questions. For short-run questions such as business cycle fluctuations, it would be essential to have a higher frequency in the model.

${ }^{15}$ Specifically, I solve the decision rules and value functions on the grids of the state variables. Capital is a continuous variable in the model is stored in 200 log-spaced grid points, and is interpolated using the cubic spline interpolation when evaluating the expected future value. To approximate the distribution of capital (or wealth), I use a finer log-spaced grid (with 2,000 grid points). The simulation results do not change quantitatively with a greater number of grid points than these choices. More computational details are available upon request.

${ }^{16}$ See e.g., Heathcote, Perri and Violante (2010) for discussions on the observed wealth inequality across different data sets.
} 
Such features include discount factor heterogeneity (Krusell and Smith, 1998), entrepreneurs' savings (Quadrini, 2000), a highly skewed productivity process (Castaneda et al., 2003) and voluntary bequests (De Nardi, 2004) among others. ${ }^{17}$ To obtain an empirically reasonable distribution of household wealth, I take an approach following Castaneda et al. (2003) and Kindermann and Krueger (2016). The basic strategy is to augment a state of extraordinarily high productivity to capture the upper tail of the earnings distribution as in the data, and to use it to endogenously generate a highly concentrated distribution of wealth.

Specifically, I assume that $x_{i}$ can take among eight values (i.e., $N_{x}=8$ ): $x_{i} \in\left\{x_{1}, \ldots, x_{8}\right\}$ with $x_{1}<x_{2}<\ldots<x_{8}$. The first seven values are considered as ordinary productivity states while $x_{8}$ is an exceptionally productive state. Then, $\left\{x_{i}\right\}_{i=1}^{7}$ and the transition probabilities among these states, $\left\{\pi_{i j}^{x}\right\}_{i, j=1}^{7}$, are obtained as a discrete approximation of the $\mathrm{AR}(1)$ process following the Rouwenhorst (1995) method with the persistence of $\rho_{x}$ and the standard deviation of innovations $\sigma_{x}$. The 7 by 7 Markov transition matrix is then extended in a parsimonious way. First, I assume that the highest productivity state $x_{8}$ can be only reached from $x_{7}$ with the probability of $\pi_{78}=\pi_{u p}$. Second, the probability of staying in the highest state $x_{8}$ is given by $\pi_{88}=1-\pi_{\text {down }}$ and the probabilities of falling down from $x_{8}$ are equally distributed; that is, $\left\{\pi_{8 j}\right\}_{j=1}^{7}=\pi_{\text {down }} / 7$. As shown later, this marginal extension of the standard labor productivity process with three extra parameters enhances the performance of model in replicating the distributions of earnings and wealth in the SCF data.

Given the set of parameters described so far, I now discuss how these parameters are calibrated. I begin with parameters that are externally calibrated. These parameters are commonly used in the quantitative macroeconomics literature and are thus set independently of the model specification settings. The first parameter $\alpha$ in the aggregate production function is set to 0.36 , consistent with the capital share in the aggregate U.S. data. The annual capital depreciation rate $\delta$ is equal to 0.096, as is standard in the real business cycle literature. I set the hours of work $\bar{n}$ conditional on working to 0.4 , which would correspond to full-time hours of work. Regarding the ordinary productivity process, I set $\rho_{x}=0.94, \sigma_{x}=0.205$ as in Alonso-Ortiz and Rogerson (2010). Regarding the tax rates for factor income, I follow Trabandt and Uhlig (2011) who construct the effective income tax rates based on Mendoza, Razin and Tesar (1994) using the OECD's Revenue Statistics and

\footnotetext{
${ }^{17}$ See e.g., De Nardi (2015) for the survey of the literature on these features.
} 
Table 2: Parameter values chosen internally using simulation

\begin{tabular}{lrrrrl}
\hline \hline \multirow{2}{*}{ Parameter } & \multicolumn{5}{c}{ Model } \\
$\Gamma$ & $(\mathrm{a})$ & \multicolumn{1}{c}{$(\mathrm{b})$} & $(\mathrm{c})$ & $(\mathrm{d})$ & \multicolumn{1}{c}{ Description } \\
\hline & & & & & \\
$\beta$ & 1.43 & 2.81 & 1.39 & 2.92 & Disutility of work \\
$x_{s}$ & .963 & .936 & .950 & .949 & Discount factor \\
$\pi_{\text {up }}$ & 54.1 & 46.6 & 53.8 & 47.3 & High productivity state \\
$\pi_{\text {down }}$ & .00117 & .0134 & .00151 & .00890 & Prob of moving up to $x_{s}$ \\
$\phi$ & .00917 & .0953 & .0119 & .0637 & Prob of falling from $x_{s}$ \\
$\lambda_{s}$ & .111 & .0395 & .109 & .0410 & Borrowing constraint \\
$\lambda_{p}$ & .113 & & .115 & & Transfer scale \\
& 3.48 & & 3.49 & & Transfer progressivity \\
Model restrictions: & None & $\lambda_{s}=0$ & $\tau_{k}=0$ & $\lambda_{s}=0$ & \\
& & $\tau_{k}=0$ & & & \\
\hline
\end{tabular}

National Accounts. Taking the averages over 1992 to 2007, the tax rate on labor earnings $\tau_{l}$ is set equal to 0.279 and the tax rate on capital income $\tau_{k}$ is set to $0.366 .^{18}$

The second set of eight parameters are internally calibrated to match eight target statistics in the data for each model specification. In addition to the baseline specification introduced in the previous section (denoted as Model (a) henceforth), I consider three alternative specifications. These are nested versions of Model (a). Model (b) restricts transfers and the capital tax rate to be zero $\left(\lambda_{s}=\tau_{k}=0\right)$. This alternative specification serves as a benchmark environment representing the standard incomplete-markets models that abstract from government transfers and capital taxation. ${ }^{19}$ To disentangle the relative importance of transfers and capital income taxation, Model (c) keeps transfers but shuts down capital income taxation $\left(\tau_{k}=0\right)$, and Model (d) maintains capital income taxation but sets transfers to zero $\left(\lambda_{s}=0\right)$.

Table 2 summarizes the eight parameters, the values of which are jointly determined by simulating the model for each specification. Specifically, the calibrated values minimize the distance between target statistics obtained from the data and those obtained from the model-generated data. The first parameter $\Gamma$ determines the size of disutility of work. The relevant target is set as the overall employment rate of $73.6 \%$ in the samples from the SCF. The next parameter $\beta$ is the

\footnotetext{
${ }^{18}$ These tax rates are close to the values in Domeij and Heathcote (2004).

${ }^{19}$ In the literature, it is quite common to abstract from government when it comes to study labor supply in an incomplete markets framework (e.g., Chang and Kim, 2006, 2007; Domeij and Floden, 2006; Pijoan-Mas, 2006; Chang, Kwon, Kim and Rogerson, 2014 among others).
} 
Table 3: Target statistics: model vs data

\begin{tabular}{|c|c|c|c|c|c|}
\hline \multirow[b]{2}{*}{ Target statistics } & \multicolumn{4}{|c|}{ "Model } & \multirow{2}{*}{$\begin{array}{l}\text { U.S. } \\
\text { Data }\end{array}$} \\
\hline & (a) & (b) & (c) & $(\mathrm{d})$ & \\
\hline Employment rate $(\%)$ & 73.6 & 73.7 & 73.6 & 73.5 & 73.6 \\
\hline Steady-state interest rate $(\%)$ & 4.00 & 4.00 & 3.99 & 3.99 & 4.00 \\
\hline Earnings share by top $1 \%(\%)$ & 12.4 & 12.4 & 12.4 & 12.4 & 12.4 \\
\hline Earnings share by top $0.1 \%(\%)$ & 4.72 & 4.72 & 4.73 & 4.74 & 4.72 \\
\hline Wealth share by top $10 \%(\%)$ & 65.8 & 65.8 & 65.8 & 65.7 & 65.9 \\
\hline Wealth share by bottom $10 \%(\%)$ & -0.41 & -0.41 & -0.41 & -0.41 & -0.41 \\
\hline Ratio of transfers to income (\%) & 4.92 & - & 4.94 & - & 4.93 \\
\hline $\begin{array}{l}\text { Mean transfers by } 1 \text { st income quintile } \\
\text { relative to unconditional mean }\end{array}$ & 2.77 & - & 2.77 & - & 2.78 \\
\hline Model restrictions: & None & $\begin{array}{l}\lambda_{s}=0 \\
\tau_{k}=0\end{array}$ & $\tau_{k}=0$ & $\lambda_{s}=0$ & \\
\hline
\end{tabular}

discount factor, and is calibrated to match the steady state real interest rate of $4 \%$.

The next three parameters (i.e., $x_{s}, \pi_{u p}$, and $\pi_{\text {down }}$ ) are related to the extraordinary productivity. Recall that the essence of the calibration approach regarding these parameters is to generate the realistic upper tail of wealth distribution through the top earners. Therefore, these parameters are calibrated to match both the top earnings distribution and the top wealth distribution in the SCF data. Specifically, since the fraction of households at the extraordinary productivity state in equilibrium is typically less than $0.1 \%$ when using this type of approach (e.g., Castaneda et al., 2003; De Nardi, 2015), I choose the earnings share by top $1 \%$ and top $0.1 \%$ in addition to the share of wealth by top $1 \%$ as the relevant target statistics for these parameters.

The borrowing limit $\underline{a}$ is linked to aggregate output per capita by assuming $\underline{a}=-\phi Y$. Then, $\phi$ captures the tightness of overall credit markets. The relevant target for $\phi$ is chosen as the wealth share by the households near the borrowing limit (i.e., the bottom 10\%).

Finally, there are two fiscal parameters $\lambda_{s}$ and $\lambda_{p}$ regarding the nonlinear transfer schedule in Model (a) and (c). Since $\lambda_{s}$ captures the scale of transfers, the ratio of transfers to income is used as the target statistics for $\lambda_{s}$. The household-level amount of transfers is based on a broad range of government transfers in the Survey of Income and Program Participation (SIPP). ${ }^{20}$ Next, recall that $\lambda_{p}$ measures the degree of progressivity in the amount of transfers. Therefore, the last target

\footnotetext{
${ }^{20}$ See Appendix for the detailed categories.
} 
Table 4: Earnings and wealth share, by quintile of each variable: data and model

\begin{tabular}{|c|c|c|c|c|c|c|c|c|c|c|}
\hline \multirow[t]{2}{*}{ Unit: $\%$} & \multicolumn{5}{|c|}{ Earnings quintile } & \multicolumn{5}{|c|}{ Wealth quintile } \\
\hline & $1 \mathrm{st}$ & 2nd & $3 \mathrm{rd}$ & 4 th & 5 th & 1 st & 2nd & $3 \mathrm{rd}$ & 4 th & 5 th \\
\hline U.S. Data & 0.6 & 7.4 & 14.4 & 23.2 & 54.6 & -0.4 & 1.2 & 5.1 & 13.6 & 80.5 \\
\hline Model (a) & 0.0 & 7.6 & 17.5 & 25.3 & 49.7 & -0.7 & 0.6 & 5.0 & 13.6 & 81.4 \\
\hline Model (b): $\lambda_{s}=\tau_{k}=0$ & 0.0 & 6.0 & 15.1 & 24.9 & 53.9 & -0.4 & 0.5 & 3.4 & 15.7 & 80.9 \\
\hline Model (c): $\tau_{k}=0$ & 0.0 & 7.4 & 17.6 & 25.2 & 49.8 & -0.7 & 0.3 & 4.8 & 13.5 & 82.1 \\
\hline Model (d): $\lambda_{s}=0$ & 0.0 & 5.9 & 15.0 & 25.2 & 54.0 & -0.4 & 0.5 & 3.3 & 15.7 & 80.8 \\
\hline
\end{tabular}

Note: The first row for the U.S. is obtained from the author's calculations using data from the 1992-2007 waves of the Survey of Consumer Finances.

statistic is set as the mean transfers among the first income quintile relative to the unconditional mean transfers. The above calibration strategy makes sure that the amount of transfers received by the poor households in the model is in line with the data.

Table 3 shows that the model does a very good job of matching the target statistics in all of the specifications. The above calibration strategy also implies that all specifications have the same macroeconomic aggregate ratios such as the capital-to-output ratio (2.65) and the capital-to-labor ratio (4.58). However, this does not necessarily mean that the different specifications have the same predictions along other non-targeted dimensions. Therefore, Table 4 and Table 5 present several important non-targeted statistics regarding distributions of households under the different model specifications.

I begin by examining earnings distributions implied by different specifications of the model economy. In the left panel of Table 4, the share of earnings held by each quintile is reported. Although the model is calibrated to match only the very top of the earnings distribution, the model actually does a good job of accounting for the overall dispersion of earnings. For instance, the share of earnings held by the top quintile is close to $50 \%$ in Model (a) and Model (c) and is around 54\% in Model (b) and Model (d). These are quite close to 54.6 percent in the data. The model-implied share of earnings in the other quintiles are also broadly consistent with the data. Table 4 also reports the share of wealth by wealth quintile both from the data and from the model economy across different specifications. Although the calibration only targets the bottom $10 \%$ and 
Table 5: Transfers by income quintile: models vs data

\begin{tabular}{lccccc}
\hline \hline Unit: \% & \multicolumn{5}{c}{ Income quintile } \\
\cline { 2 - 6 } & 1st & 2nd & 3rd & 4th & 5 th \\
\hline \multirow{2}{*}{ U.S. Data } & 2.78 & 0.95 & 0.62 & 0.38 & 0.27 \\
& & & & & \\
Model (a) & 2.77 & 1.14 & 0.60 & 0.35 & 0.14 \\
Model (c): $\tau_{k}=0$ & 2.77 & 1.13 & 0.60 & 0.36 & 0.14 \\
\hline
\end{tabular}

Note: Reported values are the average transfers in each income quintile relative to the unconditional mean transfers. U.S. data are based on the Survey of Income and Program Participation.

the very top of the wealth distribution, the model does a very good job of producing an endogenous distribution of wealth, which is well in line with the data. Specifically, in both the model and the data, the first two wealth quintiles hold a very tiny fraction of wealth of the overall economy whereas the highest two wealth quintiles hold close to $95 \%$ of the total wealth of the economy.

Finally, note that Model (a) and Model (c) incorporate a nonlinear schedule of transfers which is only targeted to match the unconditional mean transfers and the conditional mean transfers among the first income quintile. Given that a specific functional form is chosen to fit the data, it is interesting to check how the model performs in other income quintiles as well. To see this, Table 5 reports the conditional mean transfers by income quintiles relative to the unconditional mean transfers. The first row shows that a sizeable degree of heterogeneity in the amount of transfers by income quintile in the U.S. For example, the mean transfers among the first income quintile is nearly three times as large as the unconditional mean transfers while the mean transfers among the third quintile is about $60 \%$ of the unconditional average transfers. The second and third rows show that the model with the simple functional form in (6) is able to match not only the targeted moment for the first quintile but also the overall shape of progressivity in the household-level transfers in the data.

\section{Quantitative analysis of wealth and employment}

The exercises in the previous section suggest that the assumptions on institutional settings such as transfers and capital taxation may not be crucial in matching the marginal distribution of wealth. In this section, however, I show that these institutional factors are crucial when it comes to the 
(non-targeted) joint distribution of wealth and employment. ${ }^{21}$

I begin by presenting the key results on the role of transfers and capital income taxation in rendering the prediction of standard incomplete markets models more consistent with the data regarding the wealth-employment relationship. Figure 2 displays conditional employment rates by wealth quintile implied by Model (a) that incorporates both transfers and capital income taxation (blue dotted line) as well as Model (b) that shuts down transfers and capital income taxation (red dashed line). I also present the data benchmark (green solid line) along with the model results. ${ }^{22}$ First, note that Model (b) predicts that labor supply strongly declines with wealth, which is consistent with the previous findings using incomplete markets models (Chang and Kim, 2007; Mustre-del-Rio, 2015; and Ferriere and Navarro, 2016). This steep negative gradient is in sharp contrast to what we observe in the data showing that labor supply behavior at the extensive margin does not have a clear monotone relationship with wealth, as documented in Section 2 .

A striking result to note in Figure 2 is that Model (a) does a great job of replicating the weakly inverse U-shaped employment-wealth profile in the data. Specifically, the employment rate among the bottom wealth quintile in Model (a) is $60.2 \%$, which is much closer to the data (60.8\%). In addition, the employment rate among the top wealth quintile is considerably higher (71.3\%) in Model (a), much closer to the data (72.3\%) relative to a low employment rate of $42.0 \%$ implied by Model (b).

Although the discrepancy in employment rates by wealth quintile in the data and in the model has been discussed in the literature, one of the contributions of this paper is to document correlations between wealth and employment. To this end, I compute both Spearman (rank-based) and Pearson (level-based) correlations implied by the model, and compare them to the empirical counterpart in the SCF data set. Table 6 summarizes these correlation estimates.

The third row of Table 6 reveals that both correlations implied by Model (b) are clearly negative. These estimates reflect the clearly negative relationship between employment rates and wealth in Figure 2. In particular, the rank correlation (Spearman) between wealth and employment is -0.50 , which is obviously at odds with 0.07 of the data counterpart. Pearson's correlation coefficient in Model (b) is less negative $(-0.20)$ than the rank correlation although it is quite far from its

\footnotetext{
${ }^{21}$ Some quantitative results in this section require simulated data when the discretized equilibrium distributions are not sufficient. These statistics are based on 500,000 households simulated using the model solutions.

${ }^{22}$ In Appendix, Figure $A 1$ plots the results from all model specifications but without the data.
} 
Figure 2: Participation rates by wealth quintiles: models vs data

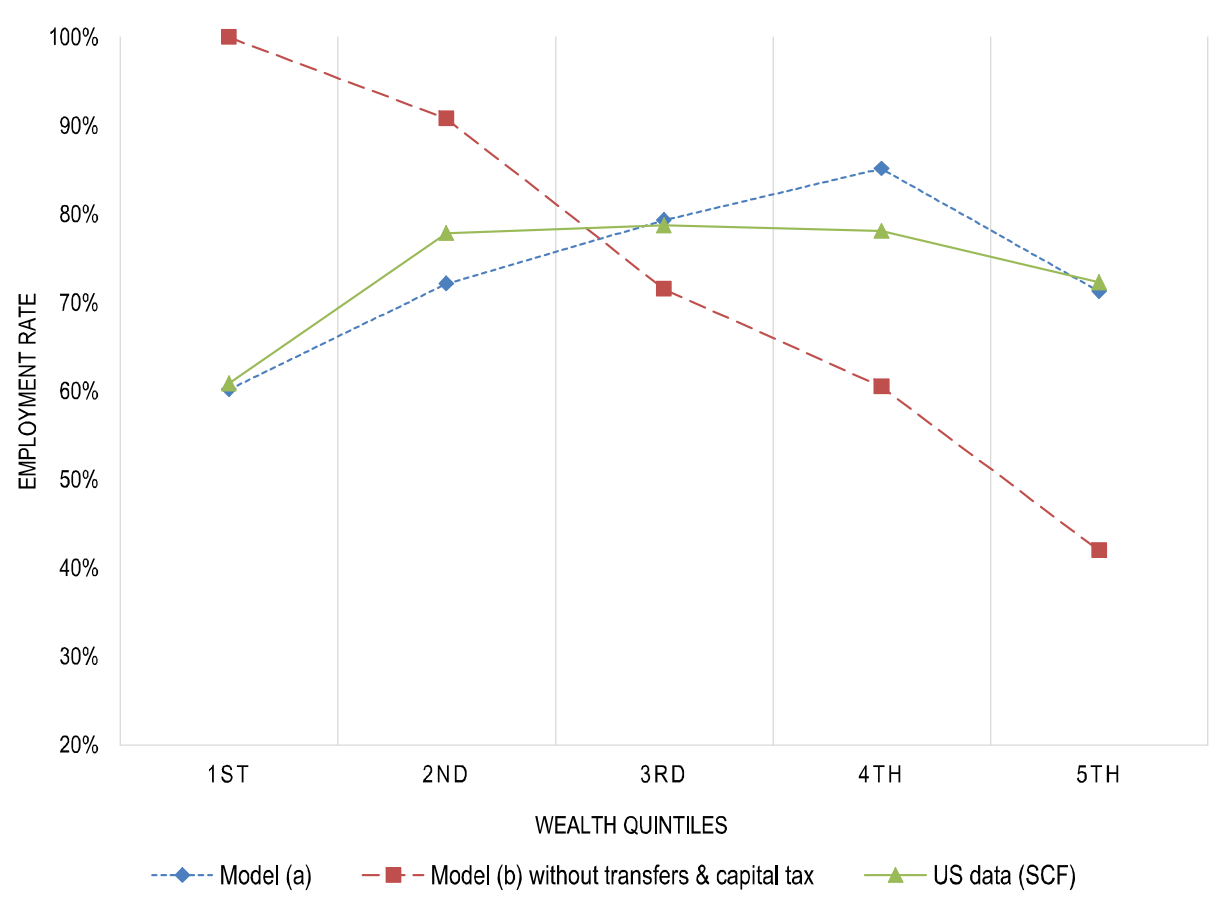

Note: Model (a), plotted with the blue dotted line, incorporates both transfers, financed by labor income taxation, and capital income taxation. Model (b), plotted with the red dashed line, restricts both transfers and the capital tax rate to be zero. Both models are recalibrated to match the common targets including the unconditional employment rate. The green solid line for the US is the same as the one in Figure 1. 
Table 6: Correlations between wealth and employment

\begin{tabular}{lcc}
\hline \hline & Spearman & Pearson \\
\hline U.S. data & 0.07 & -0.02 \\
Model (a) & 0.14 & -0.01 \\
& $(+0.63)$ & $(+0.19)$ \\
Model (b): $\lambda_{s}=\tau_{k}=0$ & -0.50 & -0.20 \\
& & \\
Decomposition: & & \\
Model (c): With only transfers; $\tau_{k}=0$ & -0.08 & -0.03 \\
& $(+0.57)$ & $(+0.17)$ \\
Model (d): With only capital tax; $\lambda_{s}=0$ & -0.46 & -0.16 \\
& $(+0.04)$ & $(+0.04)$ \\
\hline
\end{tabular}

Note: Spearman's correlation is a nonparametric measure of statistical dependence between the ranking of wealth and that of employment whereas Pearson's correlation captures the statistical dependence between the levels of the two variables. Numbers in parentheses are changes relative to the corresponding correlation in the standard version of the incomplete markets model (i.e., Model (b)).

data counterpart $(-0.02)$. The second row of Table 6 , which reports the correlations implied by Model (a), clearly shows the quantitative success of improving the model-implied cross-sectional relationship between wealth and employment. Specifically, in Model (a), Spearman's correlation turns into a positive number (0.14) and Pearson's correlation becomes very close to zero ( -0.01$)$.

The natural question that follows is which element is quantitatively more important in bringing the model closer to the data. To isolate the importance of each element for such quantitative success, it is useful to consider the nested versions of the model that shut down each element separately. Table 5 summarizes the result. Recall that Model (c) abstracts from capital taxation $\left(\tau_{k}=0\right)$ but maintains government transfers. The fourth row of Table 5 shows that Model (c) increases the correlations between wealth and employment quite substantially relative to Model (b). The presence of transfers alone increases Pearson's correlation from -0.50 to -0.08 and the Spearman correlation from -0.20 to -0.03 . This suggests that the role of transfers in improving the model's prediction on the cross-sectional relationship between wealth and employment is quantitatively substantial. Next, consider Model (d) which only incorporates capital income taxation and shuts down transfers $\left(\lambda_{s}=0\right)$. The last row of Table 5 shows that Model (d) moderately increases Spearman's correlation to -0.46 and Pearson's correlation to -0.16 , both of which are a bit closer 
to the data. This suggests that the capital tax rate does improve the model fit but it is not as powerful as government transfers in improving the cross-sectional relationship between wealth and employment.

\section{Inspecting the mechanism:}

I now investigate the mechanism through which transfers and capital taxation affect the crosssectional relationship between wealth and employment. Figure 3 illustrates the role of the presence of transfers and capital taxation through Model (a) while holding the equilibrium prices constant. Specifically, the top panel of Figure 3 plots employment rates by wealth quintile in the cases when the scale of transfers is reduced from $\lambda_{s}=0.113$ (dotted line) to 0.8 (dashed line) and 0.0 (solid line). The bottom panel of Figure 3 plots the same statistics when the capital tax rate is reduced from $36.6 \%$ (dotted line) to 19\% (dashed line) and 10\% (solid line). These exercises shut down general equilibrium considerations by holding the equilibrium prices fixed at the baseline level in order to illustrate the partial effects of each channel more clearly.

The top panel of Figure 3 clearly shows that a smaller scale of transfers increase the employment rates across the whole distribution through income effects on labor supply. More importantly, note that this effect is particularly stronger among the first and second wealth quintiles. This substantial change in the labor supply behavior of these households who hold relatively few asset holdings is driven by heightened precautionary labor-supply motives. Since the wealth poor households lack savings and are near the borrowing constraint, their consumption would become very low (especially so in the absence of government transfers) if they choose not to work. It is important to note that this concern for hitting zero consumption is relevant not only in the current period but also in the near future periods since low productivity is expected to be persistent. This significantly increases their value of working relative to the value of not working, leading to a stronger incentive to work even if their productivity (or market wage) is low. This is why the upper panel of Figure 3 shows that the reduced amount of transfers induces more of the wealth poor households to work, thereby making the relationship between employment and wealth more negative.

The bottom panel of Figure 3 shows that a lower capital tax rate tends to reduce employment rates across the whole distribution. Intuitively, a lower capital tax encourages capital accumulation, which in turn discourages labor supply due to income effects. More importantly, notice that the 
Figure 3: Effects of transfers and capital taxation on participation rates by wealth quintiles (i) The role of transfers

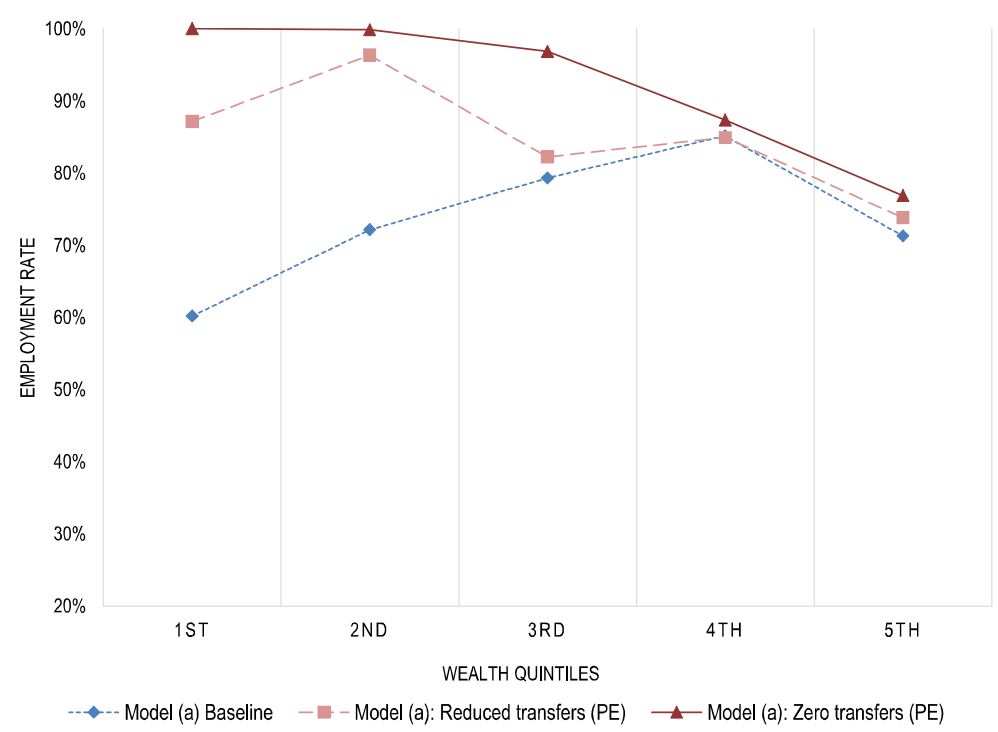

(ii) The role of capital income taxation

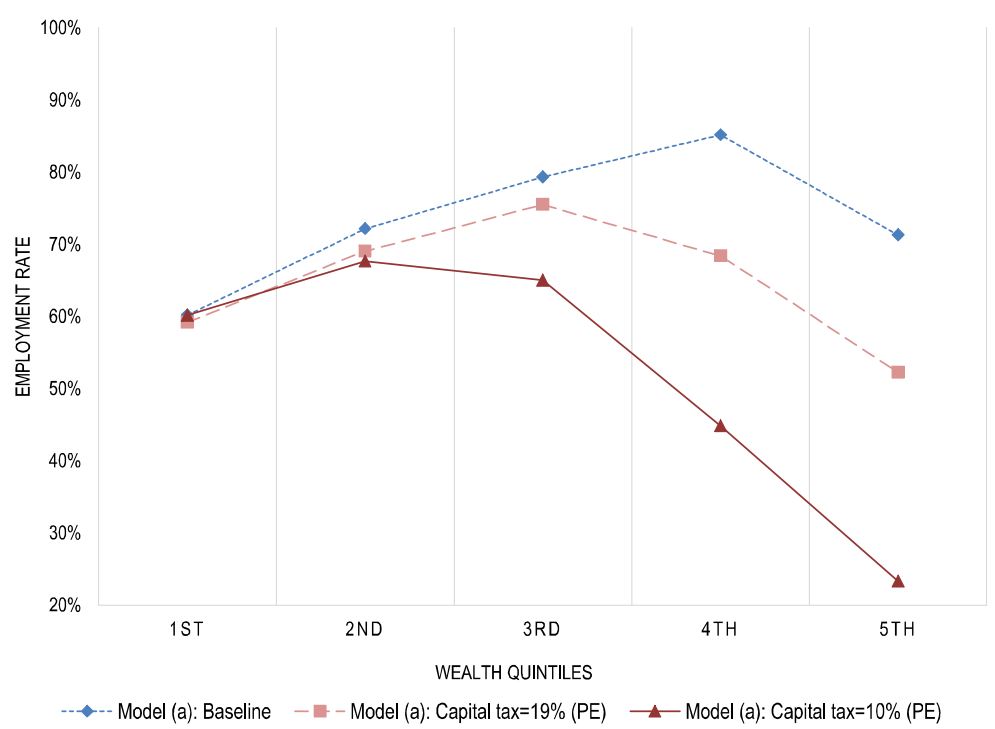

Note: In the top panel, the size of transfers is reduced while holding equilibrium prices constant at the baseline level. In the bottom panel, the capital tax rate is reduced while holding equilibrium prices constant at the baseline level. 
employment-wealth relationship becomes more negative when the capital tax rate approaches zero. This is because the decline in the employment rate is more prominent for the richer households. Since the distribution of wealth is highly concentrated (in both the model and the data), capital income is also highly concentrated. When the capital income tax rate declines, the wealth rich, who have a sizeable amount of capital income, benefits more in terms of capital gains. This means that the absence of capital taxation disproportionately encourages the savings decision of the wealth rich, which in turn implies a stronger decrease in labor supply among the wealth rich through income effects. To sum up, capital income taxation works as a mechanism that helps overturn the counterfactual negative relationship between wealth and employment through its disproportionate impact on richer households.

I now present some empirical evidence that supports the above mechanism in the micro data. Since it is hard to obtain micro-level data on capital income taxes, I focus on the relationship between transfers and labor supply using the SIPP samples used in calibration. Table 7 reports the cross-sectional relationship between transfers and employment in the total samples by estimating a linear probability model. ${ }^{23}$ Note that there is a significantly negative relationship between transfers and employment (-.0000333) with a considerably high t-statistic (or equivalently a very small standard error) in Column (1) of Table $7 .{ }^{24}$ Although this may not necessarily capture a causal effect of transfers on employment, it is interesting to note that this negative association still exists and is quantitatively robust (ranging around -.00003) even after controlling for various characteristics such as age, gender, race, and the number of children.

Since the theoretical mechanism highlighted above relies on a stronger effect of transfers on employment among the wealth poor households who are subject to a higher degree of precautionary labor supply motives, it would be interesting to examine whether the negative relationship systematically changes depending on the wealth level. Therefore, I estimate the specification (6) in Table 7 , by wealth quintile. Table 8 shows that it is indeed the case that the negative association is strongest in the first wealth quintile and its absolute value declines with the wealth quintile. For instance, the strength of the negative association in the top wealth quintile $(-.0000194)$ is less than

\footnotetext{
${ }^{23}$ Sampling weights and robust standard errors are used. The following results are robust when a logistic model is used.

${ }^{24}$ Since many observations have zero values in both transfers and employment, I use the level instead of logged values in the estimation.
} 
Table 7: Transfers and employment

\begin{tabular}{|c|c|c|c|c|c|c|}
\hline \multirow[b]{2}{*}{ Regressors } & \multicolumn{6}{|c|}{ Dependent variable: employment } \\
\hline & (1) & $(2)$ & $(3)$ & $(4)$ & $(5)$ & (6) \\
\hline Transfers & $\begin{array}{c}-.0000333 \\
(-141.65)\end{array}$ & $\begin{array}{c}-.0000301 \\
(-118.62)\end{array}$ & $\begin{array}{c}-.0000329 \\
(-140.68)\end{array}$ & $\begin{array}{c}-.0000334 \\
(-141.72)\end{array}$ & $\begin{array}{c}-.0000333 \\
(-140.82)\end{array}$ & $\begin{array}{c}-.0000293 \\
(-116.59)\end{array}$ \\
\hline Age & & $\begin{array}{c}-.0032118 \\
(-39.54)\end{array}$ & & & & $\begin{array}{c}-.0037246 \\
(-45.31)\end{array}$ \\
\hline Gender & & & $\begin{array}{c}-.1216502 \\
(-73.14)\end{array}$ & & & $\begin{array}{c}-.125808 \\
(-76.31)\end{array}$ \\
\hline Race & & & & $\begin{array}{c}-.0141515 \\
(-10.97)\end{array}$ & & $\begin{array}{c}-.012969 \\
(-10.16)\end{array}$ \\
\hline No. children & & & & & $\begin{array}{c}.0046345 \\
(6.22)\end{array}$ & $\begin{array}{c}-.0042329 \\
(-5.73)\end{array}$ \\
\hline$R^{2}$ & .169 & .176 & .188 & .169 & .169 & .198 \\
\hline
\end{tabular}

Note: Numbers in parentheses are t-statistics based on robust standard errors. A constant term is included in all specifications.

half of that in the bottom quintile (-.0000416). Although these are not necessarily causal effects but correlations, the monotonically weakening magnitude over wealth quintile appears to support the above mechanism that government transfers have stronger effects on labor supply among the households with relatively lower wealth accumulation.

\section{Effects of alternative preference specifications:}

The main focus of this paper is to investigate the role of potentially important factors that are often missing while maintaining a standard utility function (King et al., 1988). Since one could also conjecture that labor supply differences across the distribution of wealth would be altered by changing the preference specification, I briefly consider the possibility of accounting for the crosssectional relationship between wealth and labor supply using alternative preference specifications. Consider the constant relative risk aversion utility function:

$$
U(c, n)=\frac{c^{1-\sigma}}{1-\sigma}-\Gamma n
$$

The range of the empirical estimates of $\sigma$ (or the inverse of $\sigma$, the intertemporal elasticity of substitution) is quite wide. For example, Browning, Hansen, and Heckman (1999) and Guvenen (2006) suggest that $\sigma$ ranges from 1 to 3 whereas some papers (e.g., Gruber, 2006) find a relatively 
Table 8: Transfers and employment, by wealth quintile

\begin{tabular}{|c|c|c|c|c|c|}
\hline \multirow[b]{2}{*}{ Regressors } & \multicolumn{5}{|c|}{$\begin{array}{l}\text { Dependent variable: employment } \\
\text { By wealth quintile }\end{array}$} \\
\hline & $1 \mathrm{st}$ & 2nd & $3 \mathrm{rd}$ & 4 th & 5 th \\
\hline Transfers & $\begin{array}{c}-.0000416 \\
(-51.13)\end{array}$ & $\begin{array}{l}-.0000369 \\
(-43.02)\end{array}$ & $\begin{array}{c}-.0000292 \\
(-50.50)\end{array}$ & $\begin{array}{c}-.0000246 \\
(-46.90)\end{array}$ & $\begin{array}{c}-.0000194 \\
(-50.70)\end{array}$ \\
\hline Age & $\begin{array}{c}-.0035049 \\
(-18.56)\end{array}$ & $\begin{array}{c}-.0031763 \\
(-17.34)\end{array}$ & $\begin{array}{c}-.0060726 \\
(-32.23)\end{array}$ & $\begin{array}{c}-.0068908 \\
(-30.56)\end{array}$ & $\begin{array}{c}-.0085911 \\
(-36.26)\end{array}$ \\
\hline Gender & $\begin{array}{l}-.1163583 \\
(-30.13)\end{array}$ & $\begin{array}{l}-.0965565 \\
(-26.87)\end{array}$ & $\begin{array}{c}-.1051713 \\
(-29.98)\end{array}$ & $\begin{array}{c}-.1089978 \\
(-29.89)\end{array}$ & $\begin{array}{c}-.1454433 \\
(-37.06)\end{array}$ \\
\hline Race & $\begin{array}{c}-.0168261 \\
(-5.83)\end{array}$ & $\begin{array}{c}-.000784 \\
(-0.29)\end{array}$ & $\begin{array}{c}-.0092944 \\
(-3.25)\end{array}$ & $\begin{array}{c}-.004156 \\
(-1.45)\end{array}$ & $\begin{array}{c}.0068325 \\
(2.44)\end{array}$ \\
\hline No. children & $\begin{array}{c}.0094058 \\
(5.43)\end{array}$ & $\begin{array}{c}-.0013569 \\
(-0.83)\end{array}$ & $\begin{array}{c}-.0093521 \\
(-6.32)\end{array}$ & $\begin{array}{c}-.0137691 \\
(-8.03)\end{array}$ & $\begin{array}{c}-.0187727 \\
(-10.33)\end{array}$ \\
\hline$R^{2}$ & .212 & .184 & .229 & .233 & .209 \\
\hline
\end{tabular}

Note: Specification (6) in Table 8 is used for all regressions. Numbers in parentheses are t-statistics based on robust standard errors. A constant term is included in all specifications.

high intertemporal elasticity of substitution, thereby suggesting $\sigma<1$. Therefore, I consider two alternative values of $\sigma(2 / 3$ and 1.5) around 1 , which is the benchmark preference specification (5). Then, the model with alternative preference specifications is re-calibrated to match the same target statistics according to the calibration strategy in Section $4 .{ }^{25}$ Note that the underlying framework used for this exercise is Model (b), which abstracts from both transfers and capital taxation.

Figure 4 summarizes the results. It plots the employment rates by wealth quintile for the case with $\sigma=2 / 3$ (dotted line) and the case with $\sigma=1.5$ (dash-dot line). First, note that the model with $\sigma=2 / 3$ generates a flatter employment rates by wealth even without transfers and capital taxation. The key feature of this specification is that the intertemporal elasticity of substitution $(1 / \sigma)$ is higher at 1.5 , which makes the observed cross-sectional income effects on labor supply appear weaker. However, it is worth noting that the model with $\sigma=2 / 3$ tends to reduce the employment rates of the first two quintiles quite uniformly. Thus, the model is still unable to generate the fact that the employment rate of the first wealth quintile is noticeably lower than that among the second wealth quintile. This suggests that a stronger substitution effect alone may not be sufficient to explain the employment rates of the first wealth quintile and thus the weakly inverse

\footnotetext{
${ }^{25}$ See the calibration results in Appendix.
} 
Figure 4: Effects of the risk aversion parameter on employment rates by wealth quintiles

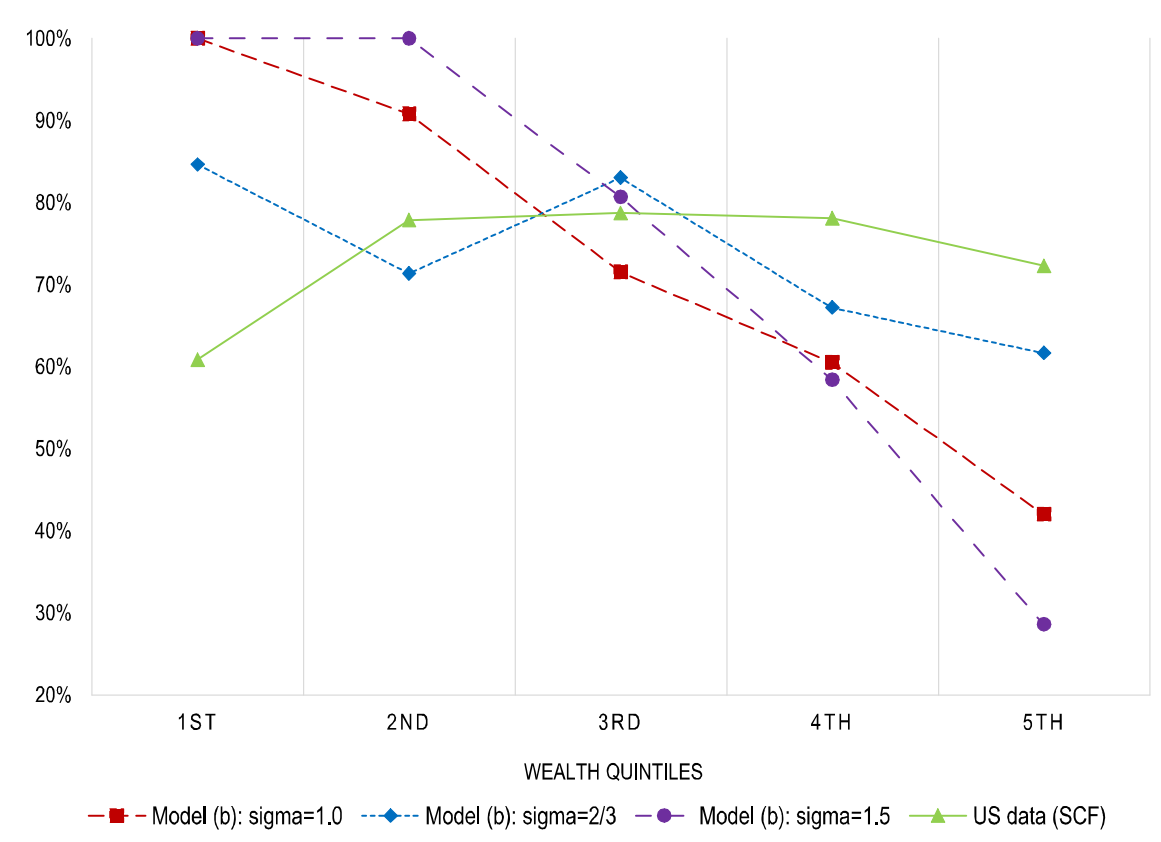

U-shaped employment rates by wealth quintile. On the other hand, the case with $\sigma=1.5$ predicts that the employment rate falls even more sharply with wealth because the elasticity of intertemporal substitution is lower at $2 / 3$, which in turn makes income effects relatively stronger. It is worth noting that, since the key mechanism through which transfers and capital taxation alter the wealthemployment relationship is the income effect on labor supply, they should have a quantitatively stronger role in resolving this counterfactually negative wealth-employment relationship in this case, compared to the baseline case with $\sigma=1$.

\section{Implications for the aggregate labor supply elasticity}

The previous section has demonstrated that incorporating transfers and capital income taxation into the standard incomplete markets model can substantially improve the counterfactually negative association between wealth and employment. Although this finding per se is important for a better understanding of incomplete markets models, this paper further asks the relevance of matching the observed employment rates by wealth in terms of the aggregate labor supply elasticity. This 
Table 9: Aggregate employment rate with respect to labor income tax changes

\begin{tabular}{lccccccc}
\hline \hline & \multicolumn{7}{c}{ Labor income tax rate $\tau_{l}$} \\
& 0.279 & 0.315 & 0.351 & 0.387 & 0.423 & 0.459 & 0.495 \\
\hline \multirow{3}{*}{$\begin{array}{l}\text { Model (a) } \\
\text { Model (b): } \lambda_{s}=\tau_{k}=0\end{array}$} & 100.0 & 98.1 & 95.9 & 94.0 & 91.7 & 89.1 & 86.0 \\
& 100.0 & 99.0 & 97.8 & 96.5 & 95.0 & 93.3 & 91.7 \\
Model (c): $\tau_{k}=0$ & 100.0 & 98.0 & 95.9 & 93.4 & 90.6 & 88.7 & 85.2 \\
Model (d): $\lambda_{s}=0$ & 100.0 & 98.0 & 96.7 & 95.5 & 94.1 & 92.6 & 91.1 \\
\hline
\end{tabular}

Note: Aggregate hours are normalized to 100 at the baseline labor income tax rate of 27.9 percent in each specification.

is particularly relevant since Chang and Kim (2006) have shown that the aggregate labor supply elasticity in this class of models is endogenously determined by the distribution of wealth.

I consider two exercises to investigate the implications for the aggregate labor supply elasticity. The first exercise considers the aggregate effects of permanent labor tax changes (see e.g., Krusell, Mukoyama, Rogerson and Şahin, 2008, 2010; and Alonso-Ortiz and Rogerson, 2010). I choose the counterfactual tax rates such that the net-of-tax rate $\left(1-\tau_{l}\right)$ is reduced by $5,10,15, .$. and $30 \% .^{26}$ The upper limit of tax rates is chosen to be $49.5 \%$, which leads to a decline of the net-of-tax rate by $30 \%$. This tax rate is very close to the recent labor income tax rates in some continental European countries such as France and Italy, based on Mendoza et al. (1994)'s method. In this experiment, I control the transfer-to-output ratio at the benchmark level with the tax rate of $27.9 \%$ for each specification. $^{27}$

Table 9 summarizes the general equilibrium effects of permanent labor income tax changes on the aggregate employment rate across different specifications considered in Section 5 . Note that the key mechanism of this paper relies on the interaction between public and self-insurance. General equilibrium allows for endogenous changes in the prices (interest rates as well as wages), which affect these interactions. The reported values are expressed relative to the case with the labor income tax rate of $27.9 \%$ that is normalized to 100 .

\footnotetext{
${ }^{26}$ This allows me to easily infer the labor supply elasticity (i.e., the percentage change in the aggregate employment rate with respect to a one percentage change in the net-of-tax rate). The resulting set of counterfactual labor tax rates is $\{0.315,0.351,0.387,0.423,0.459,0.495\}$.

${ }^{27}$ This is because the size of transfers would endogenously change when the labor income tax rate varies under the assumption of the balanced government budget constraint. This would generate additional forces that amplify the effects of tax changes, which would not exist in the absence of transfers. In order to focus on the role of transfers in shaping the distribution of wealth and employment not in amplifying the employment effects of taxes, I thus hold constant the size of transfers relative to output when the labor income tax changes, and assume that the additional tax revenue, if any, is spent as $G$.
} 
An interesting result emerges in Table 9. Comparing the first two rows, the same labor income tax changes lead to strikingly different aggregate labor supply responses. Specifically, when labor taxes are increased from $27.9 \%$ to $49.5 \%$ (as in France or Italy), Model (a) predicts that the employment rate would decrease by $14.0 \%$. This drop is substantially larger than a $8.3 \%$ fall, implied by Model (b). The results from the other specifications, Model (c) and Model (d), in the last two rows reveal that the presence of transfers amplifies the fall in aggregate employment significantly while the presence of capital taxation mitigates it marginally.

To facilitate the comparison of responsiveness to tax changes, Figure 5 plots the implied labor supply elasticity with respect to permanent tax changes, by the net-of-tax rate variations. ${ }^{28}$ In both models, a larger variation of taxes implies a greater labor supply elasticity, showing nonlinearity in the model economy. More importantly, the gap between the blue dotted line (Model (a)) and the red dashed line (Model (b)) clearly shows that differences in the estimates of the aggregate labor supply elasticities between the two models are quite substantial. Specifically, labor supply elasticities implied by Model (a) range from 0.38 to 0.46 and those implied by Model (b) ranges from 0.21 to 0.28 . If I compute the average of these elasticities within the tax variations considered herein, the aggregate labor supply elasticity implied by Model (a) is 0.42 , which is roughly $72 \%$ greater than the elasticity of 0.24 implied by Model (b). ${ }^{29}$

To understand the source of such a large discrepancy in the aggregate elasticity, it is instructive to look at labor supply behavior across the distribution of households. The first panel of Figure 6 summarizes how the employment rate in Model (a) with the baseline tax rate of $27.9 \%$ (solid line) changes when $\tau_{l}$ increases, while the third panel shows the same statistics in Model (b). Note that when tax changes, the marginal distribution of wealth in equilibrium changes but the invariant marginal distribution of productivity does not (as shown in the second and fourth panel for Model (a) and Model (b), respectively).

Figure 6 reveals important findings. First, the two models have very different implications for the type of workers who choose to work at the baseline tax rate of $27.9 \%$. More precisely, Model (a), which implies a more positive relationship between employment and wealth, shows that households

\footnotetext{
${ }^{28}$ Specifically, the labor supply elasticity plotted in Figure 5 is obtained by the percentage change in aggregate employment divided by the percentage change in the net-of-tax rate $\left(1-\tau_{l}\right)$.

${ }^{29}$ The meta-analysis in Chetty et al. (2012) finds that the steady state (Hicksian) elasticity for aggregate hours is 0.58 .
} 
Figure 5: Aggregate labor supply elasticity, by permanent net-of-tax rate variations

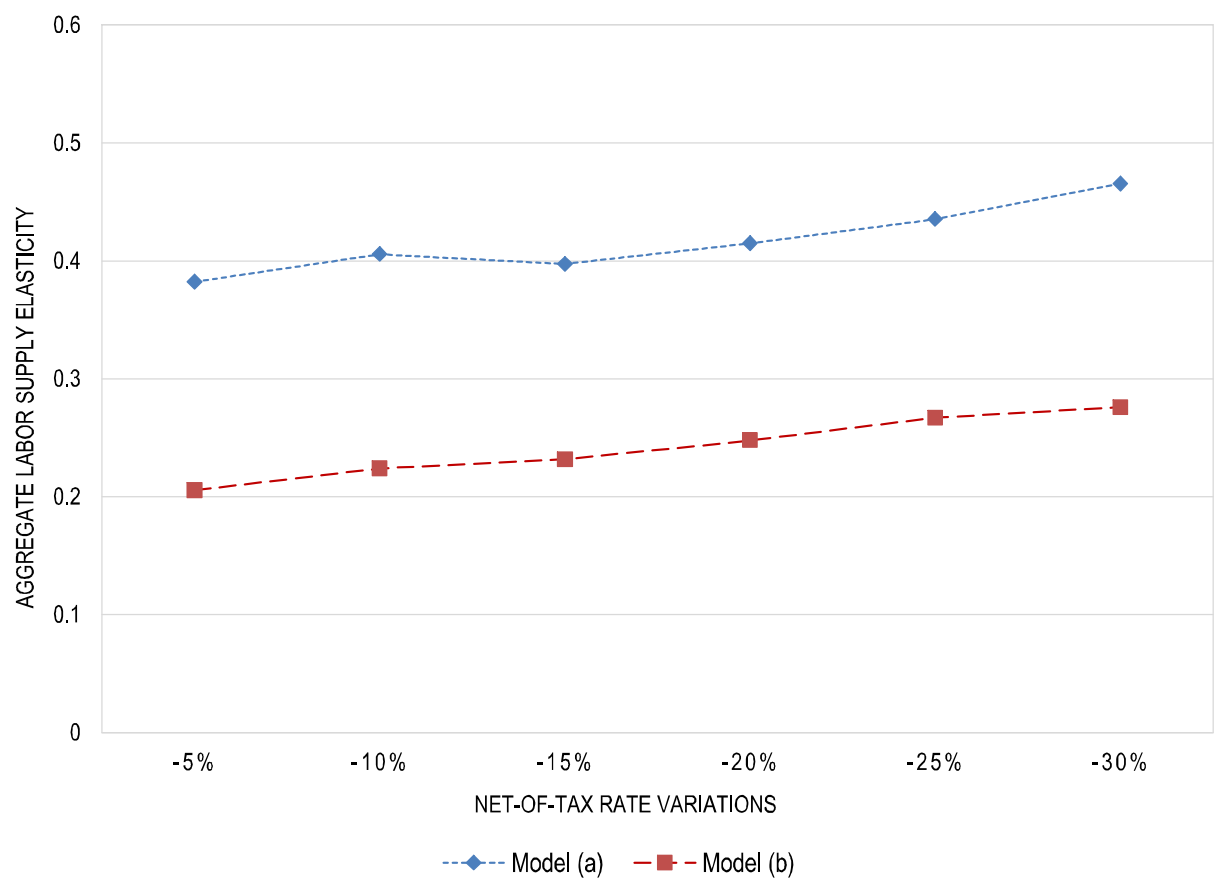

with higher productivity are considerably more likely to work. This positive relationship between productivity and employment is in sharp contrast to the V-shaped relationship in Model (b). Recall that when the model does not incorporate transfers as in Model (b), precautionary motives induce many of the wealth-poor households to work despite their low productivity. Therefore, we can see that the precautionary motive of labor supply overturns the positive relationship between productivity and employment among the households with relatively low productivity who tend to be wealth poor as well..$^{30}$

Second, the precautionary motive of labor supply also affects the labor supply elasticity of the households, especially those who have low productivity. To see this point more clearly, Figure 7 plots the percentage point changes in employment instead of the employment levels in Figure 6. A clear pattern, both in Model (a) and Model (b), is that the labor supply of households with lower

\footnotetext{
${ }^{30}$ This finding is in line with the literature (Pijoan-Mas, 2006; and Heathcote, Storesletten and Violante, 2008, 2014) highlighting the correlation between wages and intensive-margin hours to measure the degree of risk-sharing in the presence of incomplete markets.
} 
productivity tends to be more elastic to permanent tax changes. ${ }^{31}$ This implies that the aggregate labor supply elasticity is largely shaped by the responsiveness of low productivity households. However, there is a large difference in the degree of the responsiveness. Specifically, in the presence of transfers as in Model (a), households with relatively low productivity are substantially more responsive to the same percentage change in the net-of-tax rate than in Model (b) that abstracts from transfers. As the households have to rely heavily on labor supply for self-insurance in the absence of government transfers, they are less likely to be responsive to the permanent tax changes in Model (b).

Another way to investigate the model-implied labor supply elasticity is to utilize the reservation wage distribution (Chang and Kim, 2006). More precisely, once the reservation wage is calculated for each individual in the economy, the inverse of the cumulative distribution function of reservation wages provides an aggregate labor supply schedule. Chang and Kim (2006) derives an aggregate labor supply elasticity from the slope of the aggregate labor supply curves around the current employment rate. They note that the elasticity obtained using this methodology should be viewed as an upper bound for the aggregate labor supply elasticity since the distribution of wealth is held constant in this exercise. ${ }^{32}$

Figure 8 shows the aggregate labor supply curves in Model (a) (blue solid line) and Model (b) (red dashed line) constructed in this way. ${ }^{33}$ A quick look at Figure 8 shows that the aggregate labor supply curve in Model (a) is generally flatter than that in Model (b), suggesting that the aggregate labor supply elasticity should be larger in Model (a). More precisely, using \pm 5 percent variations around the employment rate of 73.6 percent, Model (b) delivers the elasticity of 1.09, which is well in the range of the elasticities of 0.94 and 1.12 in Chang and Kim (2006). However, the elasticity obtained in Model (a) is 1.74, which is considerably larger than 1.09 in the standard version of the model. Note that this result is consistent with the above finding that aggregate hours respond much more strongly to permanent tax changes in Model (a) relative to Model (b).

Interestingly, in a related paper, Mustre-del-Rio (2015) finds that introducing minimum con-

\footnotetext{
${ }^{31}$ Note that employment rate of households with the lowest two productivity levels in Model (a) is already zero at the baseline tax rate. This leads to zero employment responses to higher taxes.

${ }^{32}$ They indeed find that the elasticities obtained in this way are quite similar to the Frisch elasticity based on the model-generated aggregate data through the lens of the representative-agent model.

${ }^{33}$ The figure excludes the top $1 \%$ of the reservation wage distributions since they are substantially higher, which would make it hard to compare the two curves.
} 
Figure 6: Employment rates by (log) productivity
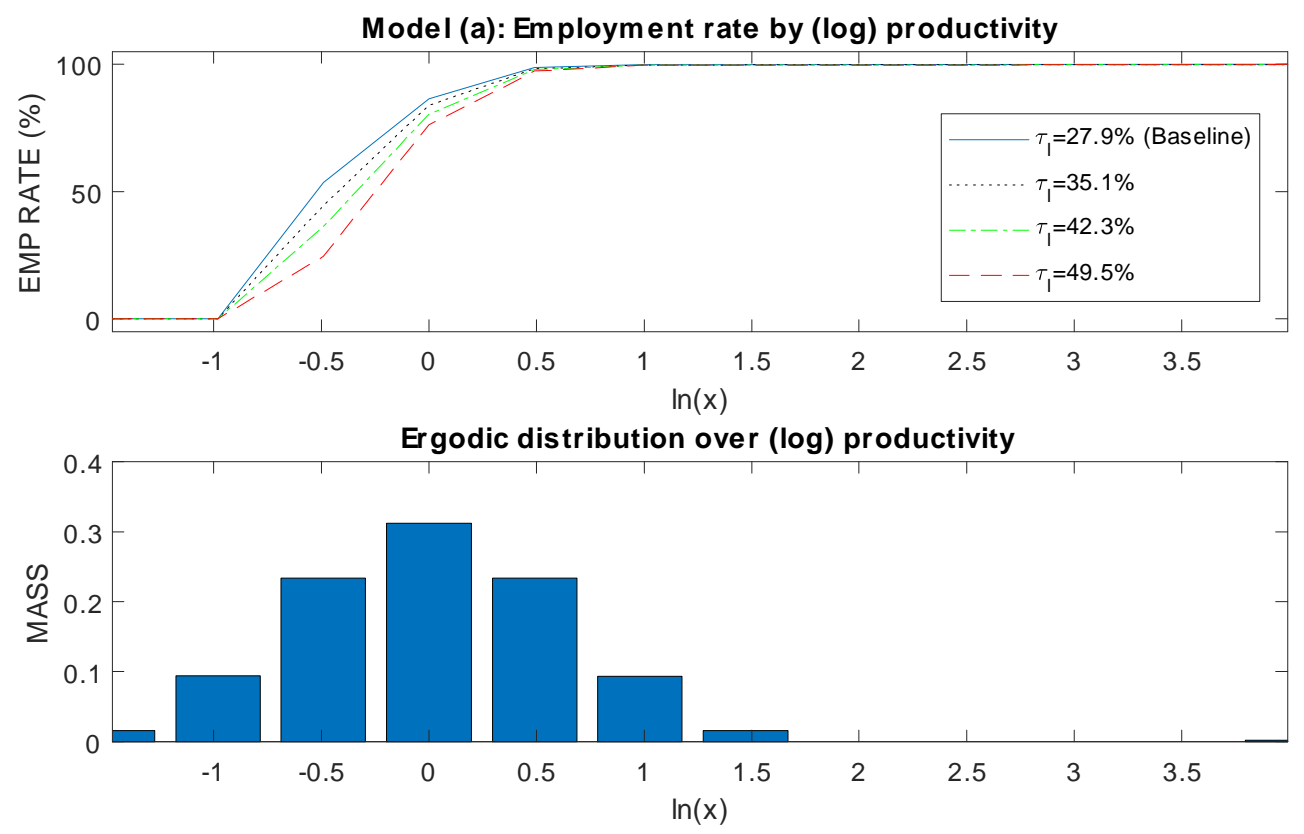

Model (b): Employment rate by (log) productivity

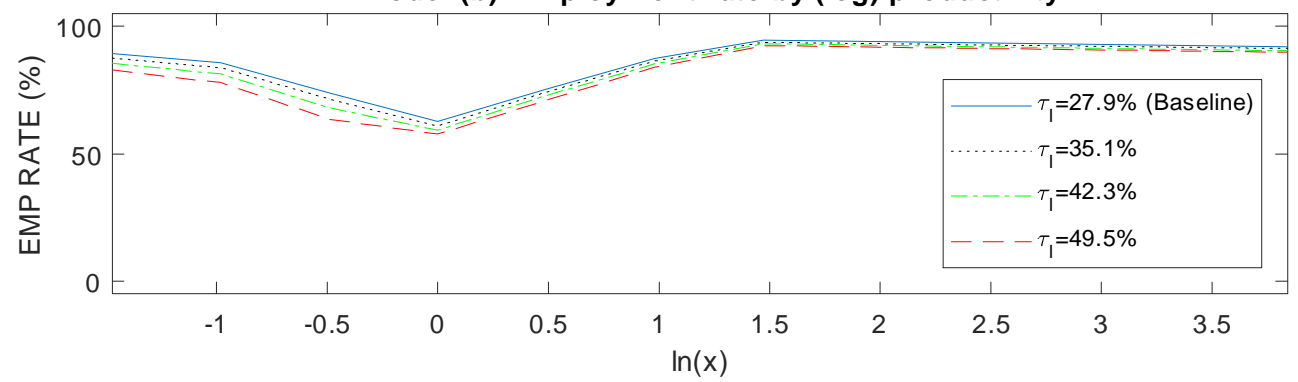

Ergodic distribution over (log) productivity

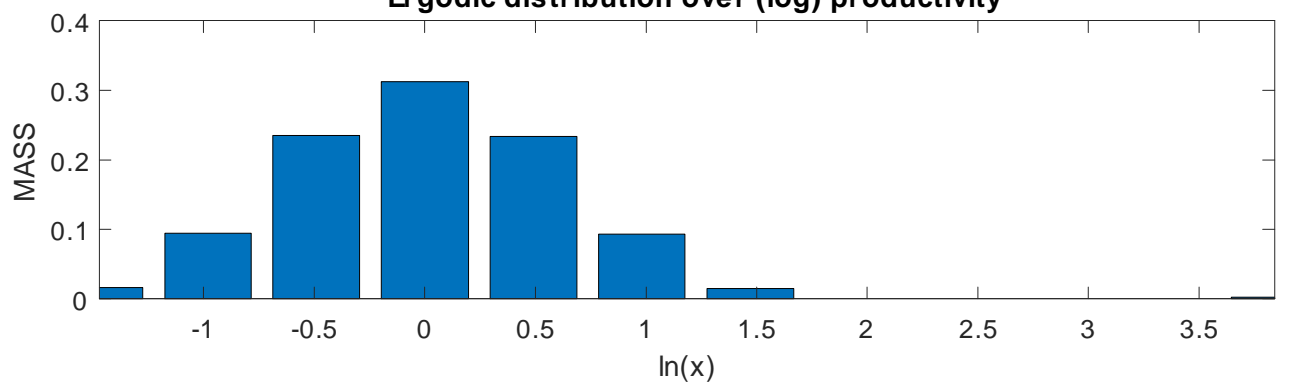


Figure 7: Employment changes by (log) productivity
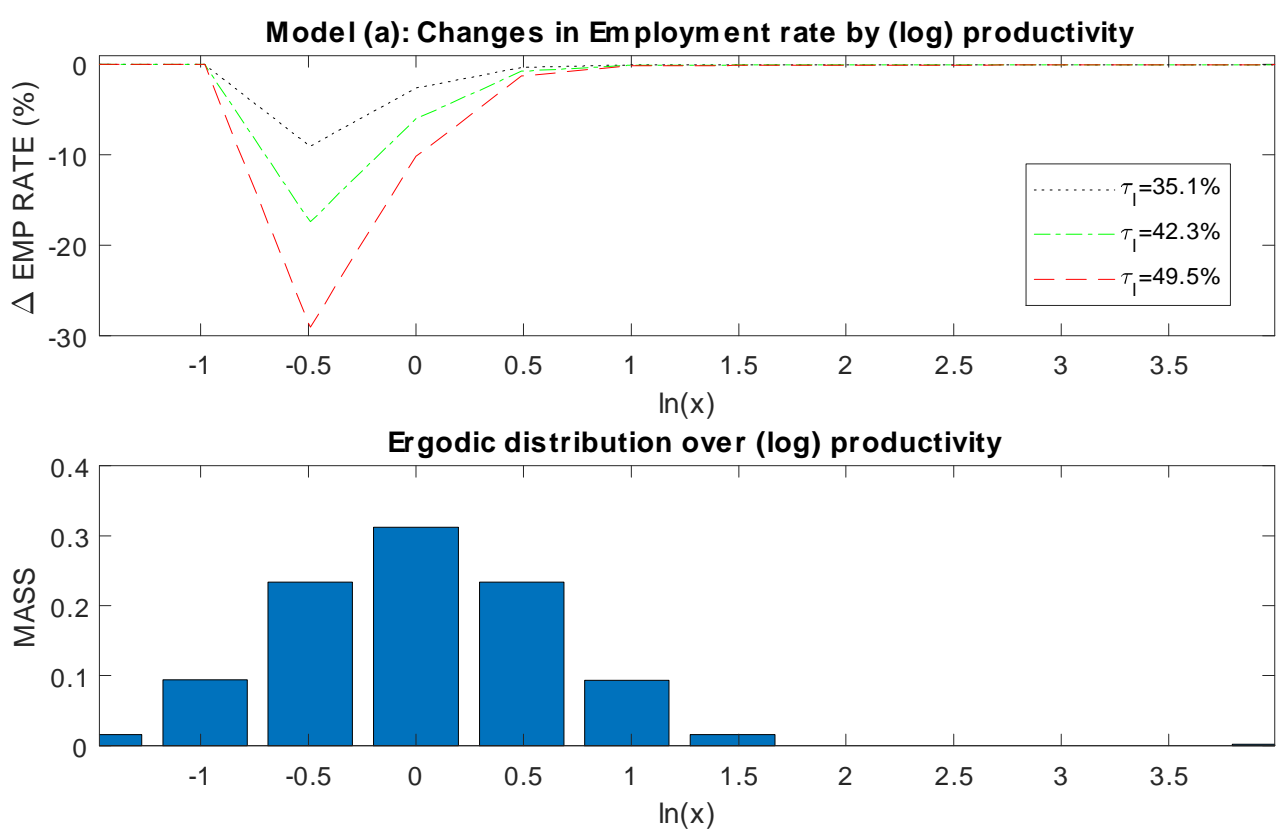

Model (b): Changes in Employment rate by (log) productivity

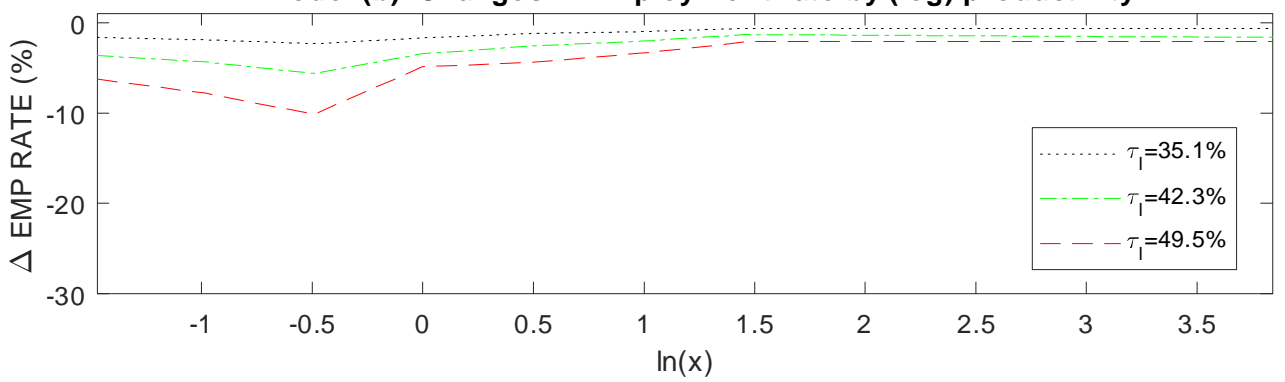

Ergodic distribution over (log) productivity

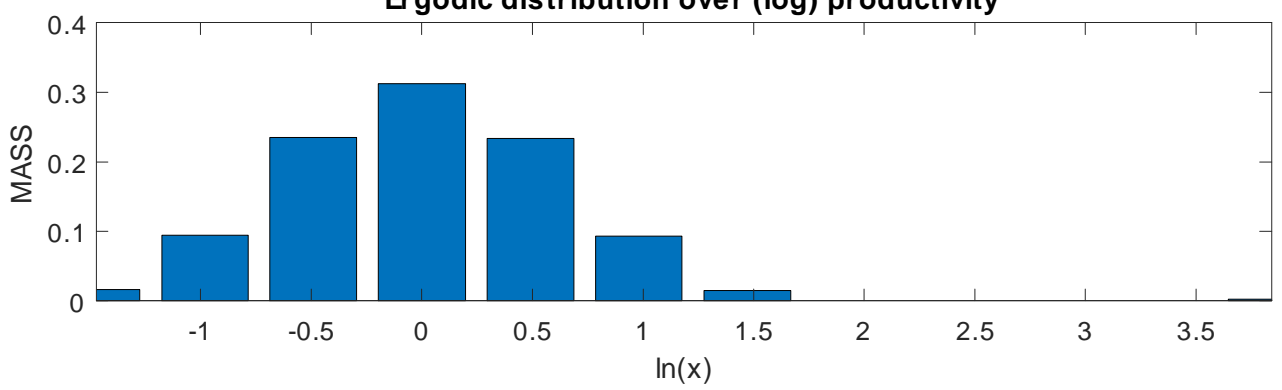


Figure 8: Reservation wage and employment rates in Model (a) and Model (b)

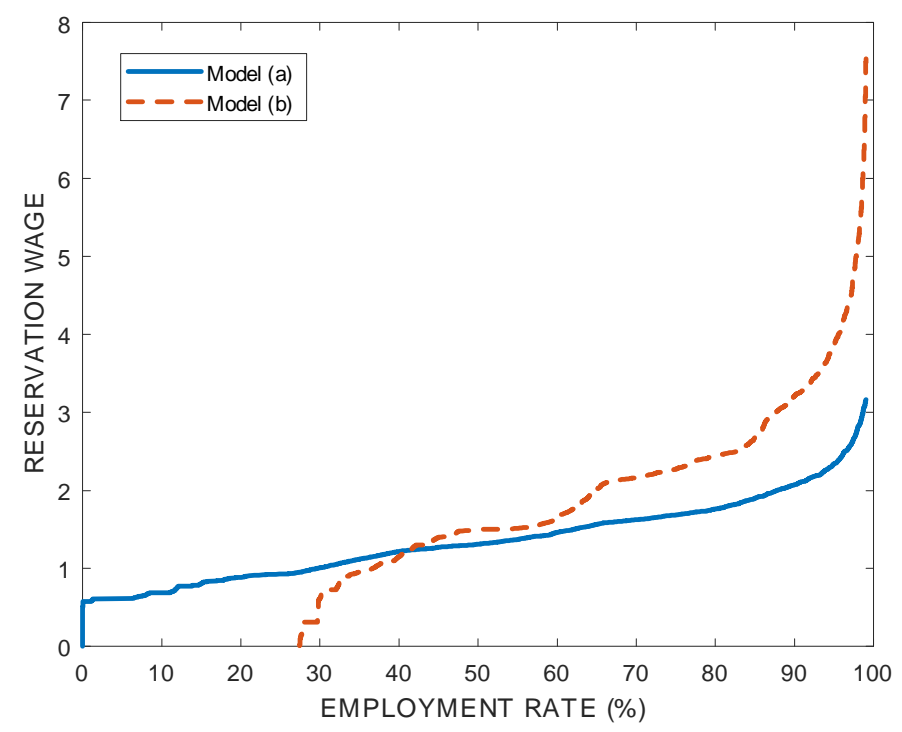

Note: The figure is constructed as the inverse cumulative distribution function of reservation wages in each economy. Wages are relative to the mean worker wage in the corresponding economy.

sumption (a form of transfers) reduces the aggregate labor supply elasticity substantially (in Table 8, Mustre-del-Rio, 2015). Hence, my results that the presence of transfers substantially increases labor supply elasticities may seem contradictory to his result. There are at least two possibilities that can explain the difference. The first is that transfers in Mustre-del-Rio are modeled as minimum consumption. When the size of minimum consumption is held fixed (as a parameter), an exogenous increase in wages inevitably reduces the (relative) degree of social insurance. According to my result, a lower degree of social insurance leads to less elastic employment decisions due to stronger precautionary motives. A related finding can be also seen in Domeij and Floden (2006) who show that the intensive margin labor supply elasticity can be attenuated near the borrowing constraint. My result is consistent with and is a natural extension of Domeij and Floden's result in the sense that mitigating the lack of self-insurance with government transfers makes the poor households who are near the borrowing constraint more elastic in their extensive margin labor supply decisions.

Another notable difference between Mustre-del-Rio (2015) and my paper is the characteristics of samples used for the quantitative analysis. Mustre-del-Rio's analysis is based on the prime-aged 
single cohort using the NLSY, which limits wealth dispersion. Furthermore, due to some properties of the NLSY survey such as top-coding, wealth concentration is further limited. In contrast, the samples using the SCF and SIPP in the current paper cover a more representative population. As a result, there are considerably more households with low wealth in addition to a much higher wealth concentration at the top. These characteristics of wealth distribution are an important determinant of the strengths of precautionary motives, which in turn are important for the labor supply elasticity results.

To sum up, the exercises in this section clearly show that the aggregate labor supply elasticity is considerably higher in Model (a) than in Model (b). The results highlight that improving the fit of the model with the cross-sectional relationship between wealth and employment matters not only for distributional properties in stationary environments, but also for the comparative static behavior of the model economy.

\section{Concluding remarks}

In this paper, I have documented that employment rates are weakly U-shaped across wealth quintiles, and wealth and employment are nearly uncorrelated (in level) or moderately positive (in rank), according to the SCF. In contrast to these facts in U.S. data, I have shown that the wealth gradient of employment rates is clearly negative and the correlations between wealth and employment are considerably negative in standard incomplete markets models. To explore the role of transfers and capital income taxation in resolving this discrepancy, I have constructed an incomplete markets models with different institutional settings and found that government transfers and capital income taxation are quantitatively significant in resolving the counterfactually negative correlations between wealth and employment. Further, I have shown that when the fit of the model with the distribution of wealth and employment improves, the aggregate labor supply elasticity implied by the model increases substantially, mainly driven by the mitigated precautionary motives of labor supply among the low productivity households.

A key mechanism of this paper that brings the model closer to the data is the insurance role of transfers for those who have few asset holdings. In this regard, it is worth noting that this paper abstracts from the insurance role of other potentially important factors such as spousal labor supply 
(Attanasio, Low, and Sanchez-Marcos, 2005) or the intensive margin of labor supply (Pijoan-Mas, 2006; Heathcote et al., 2008, 2014). It would be interesting to consider the role of family as an additional insurance mechanism that may interact with government policy and study which factor is quantitatively most relevant. In addition, as shown by Rogerson and Wallenius (2009), Chang et al. (2014), and Erosa et al. (2016), a model with both intensive and extensive margins can introduce a non-trivial interaction between the two margins of labor supply. These potentially important investigations are left for future work.

\section{References}

Aiyagari, S. Rao. 1994. "Uninsured Idiosyncratic Risk and Aggregate Saving." The Quarterly Journal of Economics 109 (3): 659-684.

Alonso-Ortiz, Jorge and Richard Rogerson. 2010. "Taxes, Transfers and Employment in an Incomplete Markets Model." Journal of Monetary Economics 57 (8): 949-958.

Attanasio, Orazio, Hamish Low, and Virginia Sanchez-Marcos. 2005. "Female Labor Supply as Insurance Against Idiosyncratic Risk." Journal of the European Economic Association 3 (2-3): 755-764.

Browning, Martin, Lars Peter Hansen, and James J. Heckman. 1999. "Micro Data and General Equilibrium Models." Handbook of Macroeconomics 1: 543-633.

Castaneda, Ana, Javier Díaz-Giménez, and José-Víctor Ríos-Rull. 2003. "Accounting for the US Earnings and Wealth Inequality." Journal of Political Economy 111 (4): 818-857.

Chang, Yongsung and Sun-Bin Kim. 2007. "Heterogeneity and Aggregation: Implications for LaborMarket Fluctuations." The American Economic Review 97 (5): 1939-1956.

— 2006. "From Individual to Aggregate Labor Supply: A Quantitative Analysis Based on a Heterogenous Agent Macroeconomy." International Economic Review 47 (1): 1-27.

Chang, Yongsung, Sun-Bin Kim, Kyooho Kwon, and Richard Rogerson. 2014. "Individual and Aggregate Labor Supply in a Heterogenous Agent Economy with Intensive and Extensive Margins." Working paper. 
Chetty, Raj, Adam Guren, Day Manoli, and Andrea Weber. 2012. "Does Indivisible Labor Explain the Difference between Micro and Macro Elasticities? A Meta-Analysis of Extensive Margin Elasticities." In NBER Macroeconomics Annual 2012, Volume 27: University of Chicago Press.

De Nardi, Mariacristina. 2015. "Quantitative Models of Wealth Inequality: A Survey". NBER Working Paper No. 21106.

- 2004. "Wealth Inequality and Intergenerational Links." The Review of Economic Studies $71(3): 743-768$.

Díaz-Giménez, Javier, Andy Glover, and José-Víctor Ríos-Rull. 2011. "Facts on the Distributions of Earnings, Income, and Wealth in the United States: 2007 Update." Federal Reserve Bank of Minneapolis Quarterly Review 34 (1): 2-31.

Domeij, David and Martin Floden. 2006. "The Labor-Supply Elasticity and Borrowing Constraints: Why Estimates are Biased." Review of Economic Dynamics 9 (2): 242-262.

Domeij, David and Jonathan Heathcote. 2004. "On the Distributional Effects of Reducing Capital Taxes." International Economic Review 45 (2): 523-554.

Erosa, Andrés, Luisa Fuster, and Gueorgui Kambourov. 2016. "Towards a Micro-Founded Theory of Aggregate Labour Supply." The Review of Economic Studies 83 (3): 1001-1039.

Ferriere, Axelle and Gaston Navarro. 2016. "The Heterogeneous Effects of Government Spending: It's All About Taxes." Working paper.

Floden, Martin and Jesper Linde 2001. "Idiosyncratic Risk in the United States and Sweden: Is there a Role for Government Insurance?" Review of Economic Dynamics 4 (2): 406-437.

Gruber, Jonathan. 2006. A Tax-Based Estimate of the Elasticity of Intertemporal Substitution. NBER Working Paper 11945

Guvenen, Fatih. 2006. "Reconciling Conflicting Evidence on the Elasticity of Intertemporal Substitution: A Macroeconomic Perspective." Journal of Monetary Economics 53 (7): 1451-1472.

Heathcote, Jonathan, Fabrizio Perri, and Giovanni L. Violante. 2010. "Unequal we Stand: An Empirical Analysis of Economic Inequality in the United States, 1967-2006." Review of Economic Dynamics 13 (1): 15-51. 
Heathcote, Jonathan, Kjetil Storesletten, and Giovanni L. Violante. 2016. "Optimal Tax Progressivity: An Analytical Framework." Working paper.

_. 2014. "Consumption and Labor Supply with Partial Insurance: An Analytical Framework." American Economic Review 104 (7): 2075-2126.

—. 2008. "Insurance and Opportunities: A Welfare Analysis of Labor Market Risk." Journal of Monetary Economics 55 (3): 501-525.

Hubbard, R. Glenn, Jonathan Skinner, and Stephen P. Zeldes. 1995. "Precautionary Saving and Social Insurance." Journal of Political Economy: 360-399.

Huggett, Mark. 1993. "The Risk-Free Rate in Heterogeneous-Agent Incomplete-Insurance Economies." Journal of Economic Dynamics and Control 17 (5): 953-969.

Imrohoroğlu, Ayşe. 1989. "Cost of Business Cycles with Indivisibilities and Liquidity Constraints." Journal of Political Economy 97 (6): 1364-1383.

Keane, Michael P. 2011. "Labor Supply and Taxes: A Survey." Journal of Economic Literature 49 (4): $961-1075$.

Keane, Michael P. and Richard Rogerson. 2012. "Micro and Macro Labor Supply Elasticities: A Reassessment of Conventional Wisdom." Journal of Economic Literature 50 (2): 464-476.

Kindermann, Fabian and Dirk Krueger. 2016."High Marginal Tax Rates on the Top 1\%? Lessons from a Life Cycle Model with Idiosyncratic Income Risk." Working paper.

King, Robert G. and Sergio T. Rebelo. 1999. "Resuscitating Real Business Cycles." Handbook of Macroeconomics 1: 927-1007.

King, Robert, Charles Plosser, and Sergio Rebelo. 1988. "Production, Growth and Business Cycles: I. the Basic Neoclassical Model." Journal of Monetary Economics 21 (2-3): 195-232.

Krusell, Per, Toshihiko Mukoyama, Richard Rogerson, and Ayşegul Şahin. 2010. "Aggregate Labor Market Outcomes: The Roles of Choice and Chance." Quantitative Economics 1 (1): 97-127.

. 2008. "Aggregate Implications of Indivisible Labor, Incomplete Markets, and Labor Market Frictions." Journal of Monetary Economics 55 (5): 961-979. 
Krusell, Per and Jr Smith Anthony A. 1998. "Income and Wealth Heterogeneity in the Macroeconomy." Journal of Political Economy 106 (5): 867-896.

Kuhn, Moritz and JV Ríos-Rull. 2015. "2013 Update on the US Earnings, Income, and Wealth Distributional Facts: A View from Macroeconomics." Federal Reserve Bank of Minneapolis, Quarterly Review 37 (1).

Ljungqvist, Lars and Thomas J. Sargent. 2008. "Taxes, Benefits, and Careers: Complete Versus Incomplete Markets." Journal of Monetary Economics 55 (1): 98-125.

Mendoza, Enrique G., Assaf Razin, and Linda L. Tesar. 1994. "Effective Tax Rates in Macroeconomics: Cross-Country Estimates of Tax Rates on Factor Incomes and Consumption." Journal of Monetary Economics 34 (3): 297-323.

Mustre-del-Rio, Jose. 2015. "Wealth and Labor Supply Heterogeneity." Review of Economic Dynamics 18 (3): 619-634.

Oh, Hyunseung, and Ricardo Reis. "Targeted transfers and the fiscal response to the great recession." Journal of Monetary Economics 59 (2012): 50-64.

Pijoan-Mas, Josep. 2006. "Precautionary Savings Or Working Longer Hours?" Review of Economic Dynamics 9 (2): 326-352.

Quadrini, Vincenzo. 2000. "Entrepreneurship, Saving, and Social Mobility." Review of Economic Dynamics 3 (1): 1-40.

Rogerson, Richard. 2007. "Taxation and Market Work: Is Scandinavia an Outlier?" Economic Theory 32 (1): 59-85.

Rogerson, Richard and Johanna Wallenius. 2009. "Micro and Macro Elasticities in a Life Cycle Model with Taxes." Journal of Economic Theory 144 (6): 2277-2292.

Rouwenhorst, K. Geert. 1995. "Asset pricing implications of equilibrium business cycle models." In: Cooley, T.F.(Ed.), Frontiers of Business Cycle Research. Princeton University Press, Princeton, NJ, pp. 294-330.

Trabandt, Mathias and Harald Uhlig. 2011. "The Laffer Curve Revisited." Journal of Monetary Economics 58 (4): 305-327. 


\section{A Data}

The Survey of Consumer Finances (SCF) is a triennial cross-sectional survey on the representative U.S. households. To construct the main data set that are used to compute statistics, I pool the samples in the following waves: 1992, 1995, 1998, 2001, 2004, and 2007. I consider households with both male heads and female heads. Given the focus of this paper (i.e., wealth and labor supply at the extensive margin), it is important to keep the samples who are near retirement and are recently retired. This is not only because the old population constitutes a relatively large fraction of the wealth rich but also because retirement is also an important extensive margin labor supply decision. Nevertheless, I drop the samples whose age is greater than 70 since their decisions might depend on not only economic conditions but also on the health status. Next, I drop the samples who are self-employed. When pooling the data, all dollar variables are inflation-adjusted to 2013 dollars. For all statistics reported, I use weights provided by the SCF.

To construct earnings and wealth variables, I closely follow the definitions in Diaz, Glover and Rios-Rull (2011) and Kuhn and Rios-Rull (2015). Specifically, the variable of earnings is defined as wages and salaries of all kinds plus the 86 percent of the business income such as income from professional practices, businesses, and farm sources. Wealth is defined as the net worth of a household. In other words, it is the value of financial real assets of all kinds minus the value of all kinds of liabilities. See Diaz et al. (2011) and Kuhn and Rios-Rull (2015) for details about various sub-categories of assets and liabilities that are extensively covered in the SCF data set.

To construct an employment variable, I use the household head's annual total hours of worked. The annual total hours of worked is constructed as the product of the hours worked per week and the number of work weeks. The statistics in the papers are based on the threshold value of 1000 hours for someone to be defined as employed. The threshold value changes the average employment rate, but does not alter the cross-sectional relationship between wealth and labor supply significantly.

The household-level transfer is obtained from the Survey of Income and Program Participation (SIPP). It contains rich information on various transfers. The samples considered are from the first to ninth waves of the SIPP in 2001, which covers from 2001 to 2003 . The same age restrictions are used as above. The number of observations used for the empirical analysis is 257,335 . The amount

of transfers at the household level is computed as the sum of various transfer programs including 
Table A1: Parameter values and target statistics

\begin{tabular}{|c|c|c|c|c|c|c|}
\hline \multirow[b]{2}{*}{ Parameter } & \multicolumn{2}{|c|}{ Calibrated values } & \multicolumn{4}{|c|}{ Target statistics } \\
\hline & $\sigma=2 / 3$ & $\sigma=1.5$ & Target statistics (unit: \%) & $\sigma=2 / 3$ & $\sigma=1.5$ & Data \\
\hline$\Gamma$ & 1.67 & 4.95 & Employment rate & 73.6 & 73.6 & 73.6 \\
\hline$\beta$ & .944 & .930 & Steady-state interest rate & 4.00 & 4.00 & 4.0 \\
\hline$x_{s}$ & 50.9 & 43.3 & Earnings share by top $1 \%$ & 12.6 & 12.4 & 12.4 \\
\hline$\pi_{u p}$ & .0393 & .0252 & Earnings share by top $0.1 \%$ & 4.71 & 4.71 & 4.72 \\
\hline$\pi_{\text {down }}$ & .257 & .0535 & Wealth share by top $10 \%$ & 63.9 & 65.9 & 65.9 \\
\hline$\phi$ & .121 & .0434 & Wealth share by bottom $10 \%$ & -0.41 & -0.41 & -0.41 \\
\hline
\end{tabular}

Table A2: Earnings and Wealth share, by quintiles of each variable: data and model

\begin{tabular}{|c|c|c|c|c|c|c|c|c|c|c|}
\hline \multirow[t]{2}{*}{ Unit: $\%$} & \multicolumn{5}{|c|}{ Earnings quintile } & \multicolumn{5}{|c|}{ Wealth quintile } \\
\hline & 1 st & 2nd & $3 \mathrm{rd}$ & 4 th & 5 th & 1 st & 2nd & $3 \mathrm{rd}$ & 4 th & 5 th \\
\hline U.S. Data & 0.6 & 7.4 & 14.4 & 23.2 & 54.6 & -0.4 & 1.2 & 5.1 & 13.6 & 80.5 \\
\hline Model (b) $\sigma=2 / 3$ & 0.0 & 6.5 & 16.9 & 25.6 & 51.0 & -0.6 & 1.0 & 5.7 & 14.1 & 79.8 \\
\hline Model (b) $\sigma=1.5$ & 0.0 & 6.2 & 15.1 & 24.3 & 54.3 & -0.4 & 0.1 & 2.4 & 15.1 & 82.9 \\
\hline
\end{tabular}

Note: The first row for the U.S. is obtained from the author's calculations using data from the 1992-2007 waves of the Survey of Consumer Finances.

the Supplemental Security Income, the Temporary Assistant for Needy Families, the Supplemental Nutrition Assistance Program, the Supplemental Nutrition for Women, Infants, and Children, Social Security, childcare subsidy, Medicaid, and Medicare. Household income is computed as the sum of labor income and capital income such as income from financial investment, and property income. All dollar values are inflation adjusted.

\section{B More on calibration}

Table $A 1$ reports the calibrated values for the models with different values of $\sigma$ around 1 . Recall that Model (b) without transfers and capital taxation is used as the underlying framework. Table $A 2$ reports the performance of these models in terms of earnings and wealth distributions. 
Figure A1: Participation rates by wealth quintiles: models vs data

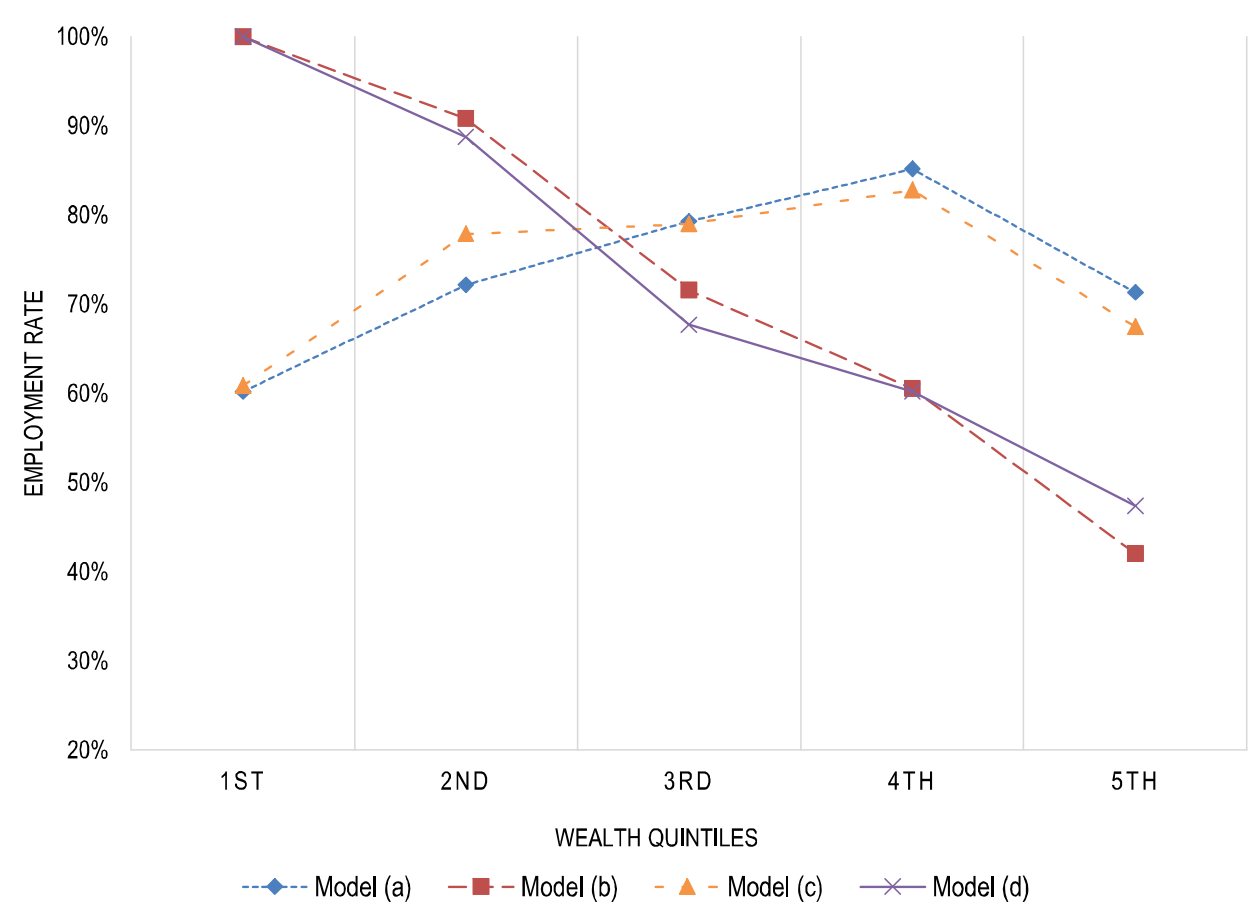

Note: Model (a), plotted with the blue dotted line, incorporates both transfers, financed by labor income taxation, and capital income taxation. Model (b), plotted with the red dashed line, restricts both transfers and the capital tax rate to be zero. Model (c), plotted with the orange dash-dot line, abstracts from capital taxation only. Model (d), plotted with the purple line, shuts down transfers only. All models are recalibrated to match the common targets including the unconditional employment rate.

\section{Additional figure}

Figure $A 1$ augments Figure 2 by plotting the employment rates by wealth quintile in all model specifications. 